\title{
التواصل الفرعي في منهجية الانثروبولوجست جريجوري باتيسون
}

\author{
د. حسين فاضل سلمان \\ كلية الآداب - جامعة بغداد
}

Abstract:

The concept of anthropologist Gregory Patson's sub-communication concept is a cross-reference to many anthropological and non-anthropological constructs through which a recombinant continuum is understood through which the group's form and social processes are understood, how the pattern is produced and reproduced again, and that the astronomy in which these concepts are based On the principle of conflict according to the biases of the spirit of the group and the spirit of personality, integration and symmetry, and the formation of splinter, which is the concept of anthropological pristine, which shows how the social interactions take their forms parallel and coherent The basic purpose of these blocks is to understand cognitive messages with the other. These theoretical manipulations have produced a comparative approach that relies on the repetitions of everyday, inward and outward behaviors (the other group), a measure of the validity of the social reference

شكل مفهوم التواصل الفرعي لدى الانثروبولوجست جريجوري باتيسون مرجعية استدماجية للعديد من المتبنيات النظرية الانثروبولوجية وغير الانثروبولوجية

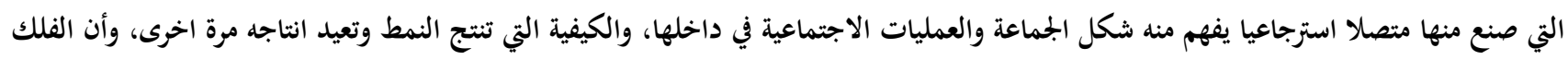

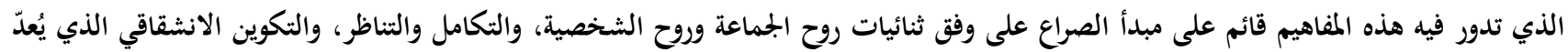

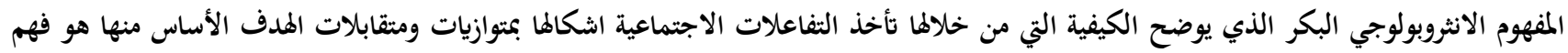

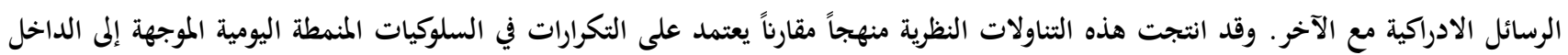
(الجماعة) والى الحارج (الجماعة الاخرى)، وهي مقياس لصدق الاخد المرجعية الاجتماتماعية.

الكملمات الدالة : التواصل الفرعي ـ المنهجية ـ جريجوري

الانثروبولوجية وهو البوتلاش والكولا، وهي عبارة عن ممارســـات ســلوكية

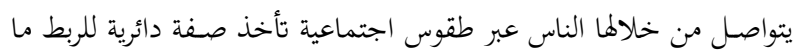

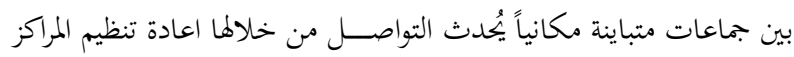
الاجتماعية وبناء السلطة والضبط والتنظيم والزعامة الدينية والوفاء بالعهود. وتشكل بجمل التناولات السابقة المنظور التبادلي في الدراسات الانثروبولوجية ولتربية التي اهتمت بفهم عملية التبادل الاجتماعي الثقافي للمجتمعات البسـيطة، واخذ هذا المفهوم بعدا اخر في دراســة الجماعات الاثنية والفرعية في المدينة تحت مسـمى التواصل الثقافي والاجتماعي للعملية الاجتماعية وفق اشكال وبناءات تبرز انماط فعل متباينة بتباين المرجعية الثقافية، وتقدم هذه الفكرة

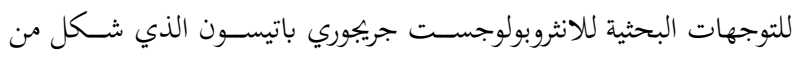

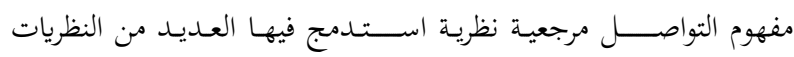
الانثروبولوجية ومن مدارس متنوعة ليشـــكل بها منهجية تكاملية تبتغي فهم تكون النمط واستمرارية الحدث.
المقدّمة:

من ابرز المثشـــكلات التي واجهها الباحثون الأنثروبولوجيون في بداية التبلور

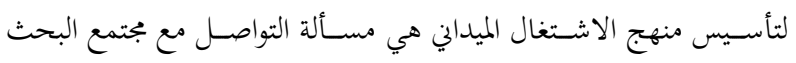

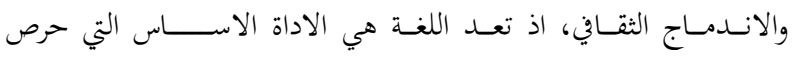

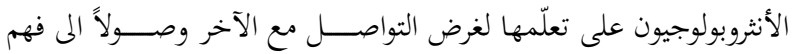

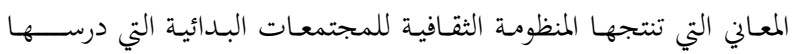

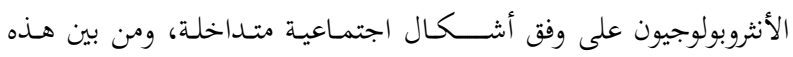
الاشكال الاجتماعية الاكثر شهرة في الدراسـات الانثروبولوجية: الطوطمية والشامانية والبوتلاش والكولا، فلكل شكل من هذه الاشكال جماعة تتبناها

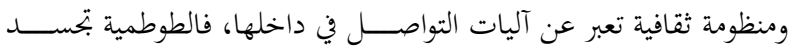

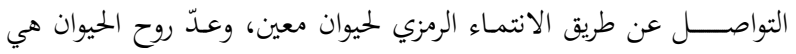
الحارســة للعشـيـة والفرد، وان التواصـل الفرعي يُحدث التبادل بالمنفعة بين الانتساب الدنيوي اي حدود العشيرة وهوية طوطمها، والجانب الغيبي الذي

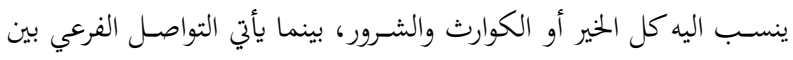
الواهب والموهوب ليشكل الشكل الاجتماعي الاكثر انتشاراً في الدراسات 
1

الصناديق النسقية المغلقة؟

2. بماذا يختلف منهج باتيسون المقارن عن التوجهات المرجعية

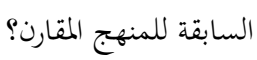

3. ماهية التواصل الفرعية لدى باتيسون، وكيف شكل نظرية

ومنهجاً لدراسة الجماعات الاثنية؟

ان مجمل ما تم طرحه من تســـاؤلات منهجية تشــــل الاجابة عنها هدفاً

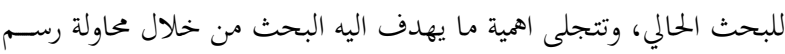

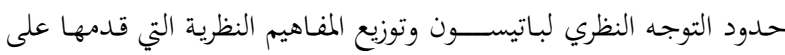
شكل ترسيمة لمنظومة تحليلية انثروبولوجية، أما على صعيد المنهج الجريجوري في الانثروبولوجيا فان التناول اعقد، وتكمن الاهمية بتحديد خطوات المنهج واليات اشتغاله في الميدان. كما تتجلى اهمية دراسة منهجية باتيسون ونظريته في التواصل الفرعي بكوها خالفت المدرسـة البريطانية الكلاسيكية وازاحت

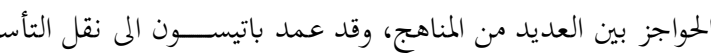

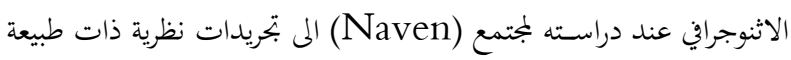
تكاملية درس عبرها الثقافات المعقدة مقارنا بين الثقافة الاميركية والثقافة البريطانية على وفق منظور الصراع والهيمنة والخضوع. ثانياً: جريجوري باتيسون ومدرسة بالو التو "التواصل الاوركسترالي":

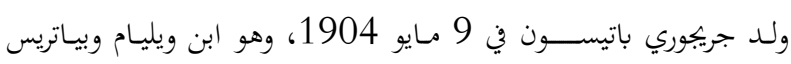
(درهام) باتيسـون. وكان لابيه شـهرة واسعة في علم الوراثة، وكانت عشـيرة باتيســون كلها بصـفة عامة ممثلة دائما بشـكل جيد في اوســاط المثقفين

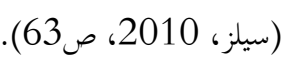

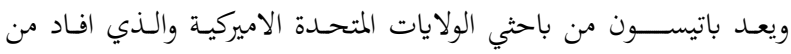
دراســات البيولوجيا وعلم النفس في دراســة الانثروبولوجيا المميزة والمبتكرة، كما طور العلاقة بين علم الاتصـــال والانثروبولوجيا، اذ قدم لدراســــات

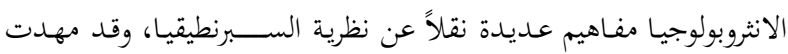
دراسـته الاثنوجرافية بعنوان (1958-Naven 1936) الطريق لمجالات كثيرة اصــبحت فيما بعد مصـــــرا للدراســـات الرمزية في الانثروبولوجيا

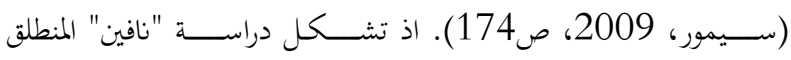

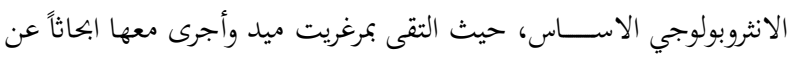

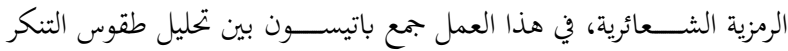
وتفكير نقدي حول طبيعة تفسـير الاحداث الاجتماعية الثقافية، تخطى باتيسون المنهج الوظيفي مما جعله يغني التفسير الاجتماعي للطقوس بدراسة

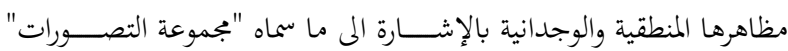
و"سـلم القيم Eidos Atethis" في ثقافة شـعب ياتمول (بونت وايزار،

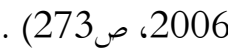

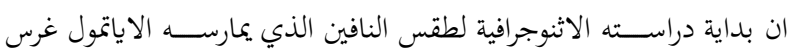
باتيسون ابتحاً منهجياً مقارناً يركز على فهم الشاذ والغريب عن طريق تحليل

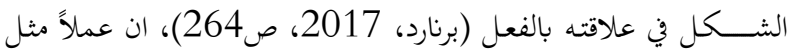

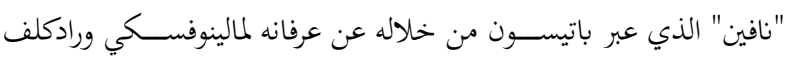

المبحث الاول: الموضوع والاهمية والمفهومات: اولا: الموضوع، الأهمية، الأهداف:

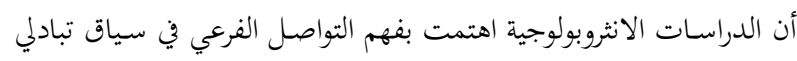

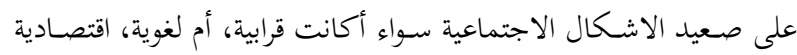

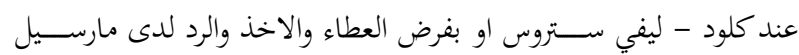
موس، وهذه التأسيسات النظرية قد بلورت مرجعية نظرية لدراسة التواصل،

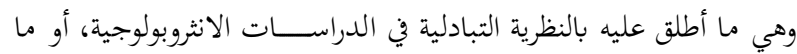
عرف على وفق منظور مارســيل موس بالوقائع الشـــمولية التي من خلالها يتواصـل افراد المجتمعات ســـواء أكانوا جماعة صـــيرة ام جماعات متفرقة. ونقصــــالوقائع الشـمولية هي دراسـة اي ظاهرة او نمط ثقافي او قرابي لا يمكن دراسـته بمعزل عن البناء الاجتماعي، بل يدرس بصـــورة شثمولية كون

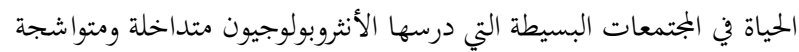
اجتماعياً وثقافياً.

ان موضـوع بحثنا يناقش ما تم تطويره من توجهات نظرية ودراسـات ميدانية

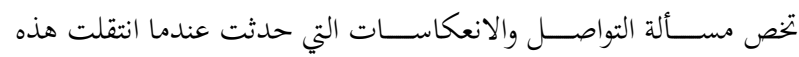
المنهجيات إلى دراســــة المدينة، اذ اختلفت المتبنيات المنهجية باختلاف المكان، ومن بين أهم هذه التوجهات يأتي جريجوري باتيسون الذي ركز على الكثير من الموضـوعات التي توزعت ما بين نظرية التعلم والسـينما والتنشـئة الاجتماعية وايكولوجيا العقل، إلا أن الإسـهام الأسـاس في دراسته الميدانية تركز على دراســة الجماعات الاثنية وحدود التواصـل الاجتماعي والصــراع الثقافي بواسـطة المنهج المقارن، وعلى الرغم من ان باتيسـون قد تتلمذ على يد كبار منظري المدرســــة الانجليزية الاجتماعية (البنائية الوظيفية) مثل رادكلف بروان وبرانسلاف مالينوفسكي الا انه طور وجهة نظر هذه المدرسة وبجاوزها من خلال منهجية تكاملية تبلورت ميدانياً في دراســـه المعروفة

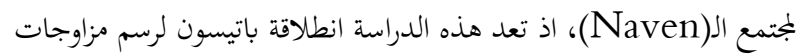
عديدة مع علم النفس والفلســفة وتوجهات المدرســة الاميركية في الثقافة، وكذلك اعادة بلورة منهجية البحث في الدراسات الانثروبولوجية بالرجوع الى لى نظرية السبرنطيقيا. إن بجمل التناولات النظرية والمنهجية وميدان اشـتغنال باتيســون تركز على لى

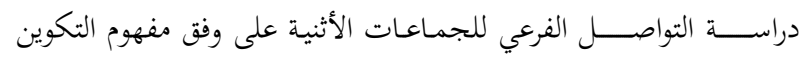
الانشـقاقي Schismegenese وهو المفهوم الاسـاس والمحوري في نظرية باتيسون ومنهجه في دراساته للتواصل الفرعي للجماعات الأثنية أو البسيطة الذي طوره ونقله إلى مديات المجتمعات الحضرية والمعقدة، اذ يتفرع من هذا

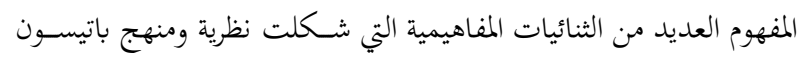
ومنها: التناظر والتكامل، السيطرة والخضوع، وهي مفاهيم سعى من خلالها لرصد (البنية الكمية) في التفاعلات الاجتماعية.

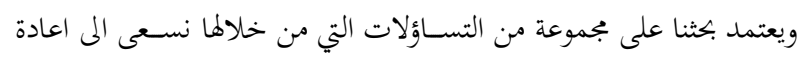

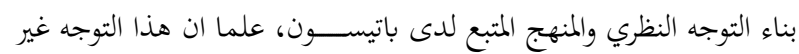
واضح بصورة اشتغالية، ولم تحدد آليات اشتغال منهجه، ولذذا الغرض نورد التساؤلات الآتية: 
موضـــوعة معينة داخل بجتمع معين تخضـــع لمنهجية تحليلية وتتبنى طابعاً تكاملياً. وهذا ما اكدت عليه مدرسـة بالو التو في اقتراحها نظرية جديدة للتواصـل تتجلى في بحاوز النموذج التواصلي الخطي المخض الذي يمثله كلود شانون، تئ

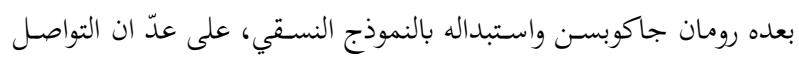
من منظور مدرسـة بالو التو اسـاس اي خلل قائم داخل النســق العائلي الاجتماعي، وتعدّ هذه المدرســة التواصـل ظاهرة اجتماعية، اذ يتم التركيز

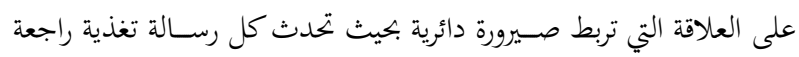
Feedback

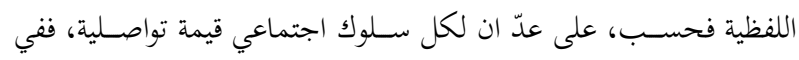

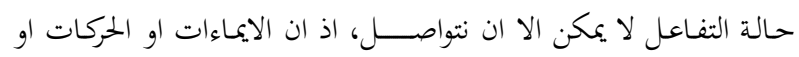
المواقف بل ايضاً القمع او الامتعاض، وكل رسالة في التصور النسقي لنظرية

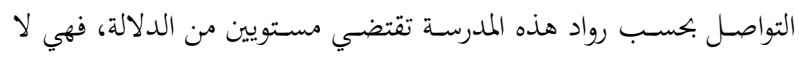

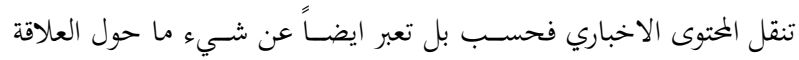

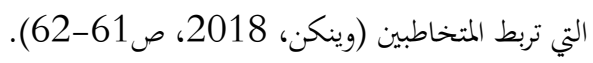

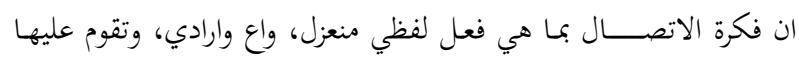
السوسيولوجيا الوظيفية، قد نقضتها فكرة الاتصال بما هو سيرورة اجتماعية

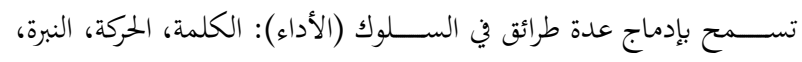

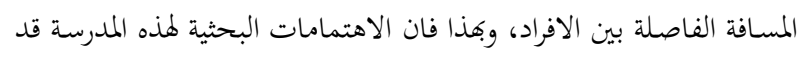
اعطت اولوية للحركة، واسـتعمال الحيز المكاني في العلاقات بين الافراد كما بينت ان السلوكيات الفردية غير السوية هي انعكاس للبيئة الاجتماعية، اي

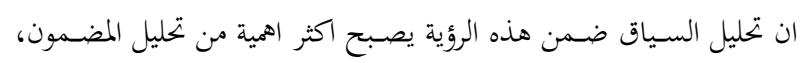

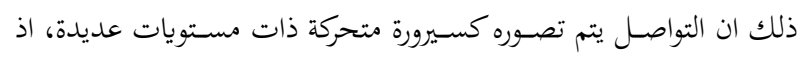

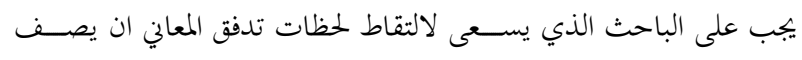

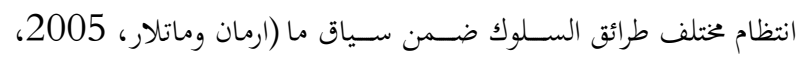
ص80-81). اذ اكدت مدرسـة بالو التو لما ســبق ذكره ان اسـتعمال

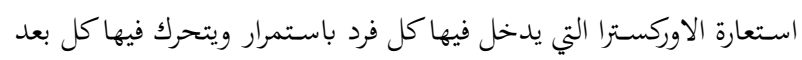

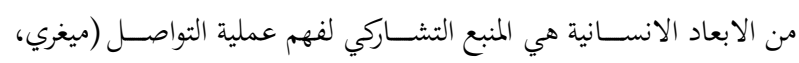

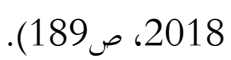
ثالثاً: ممكنات الاشتغال النظري (المنظومة المفاهيمية):

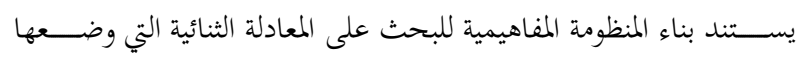

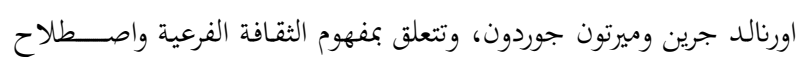
المجتمع الفرعي، وهما ينظران الى معالجة الظواهر الثقافية على اها تمثل عنصراً

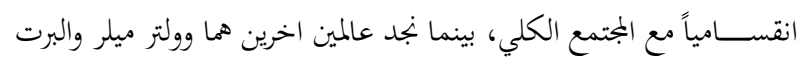
كوهين يحددان الثقافة الفرعية من خلال موجهات القيم الاساسية لاعضاء

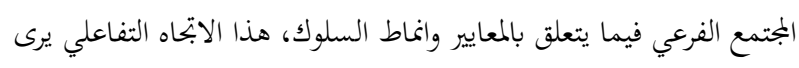

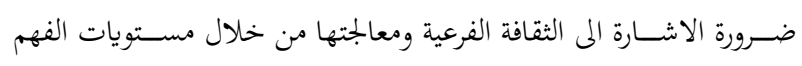
الخاصة بانماط سـلوك الجماعات، لاسيما ما يرتبط منها بالوظائف الكامنة

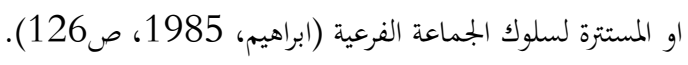

بارون وبحاوزه لمنهجيتهم في الوقت نفسـه في منهجه الذي كان يعدّ فريداً في

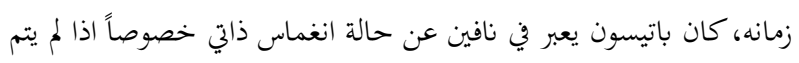

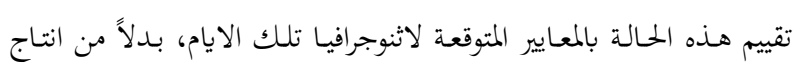

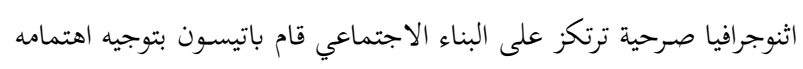

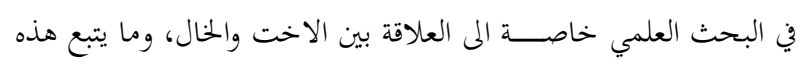
العلاقة من طقوس وشعائر خاصة، كانت اثنوجرافية باتيسون في هذا المجال

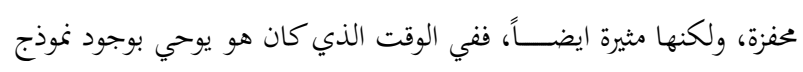

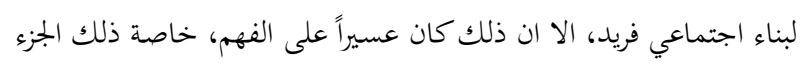
الذي يخص زواج الاجـداد بحفيداقم من البنـات، كان من المتوقع ان يقوم

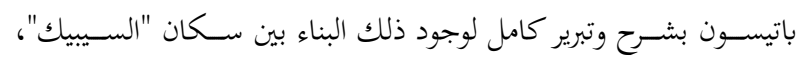

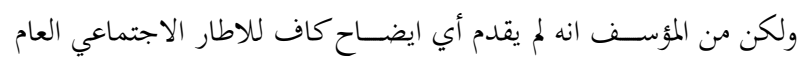

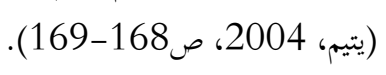

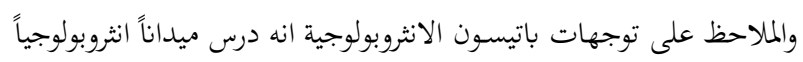
خالصاً باتجاهات نظرية متصارعة ومتباعدة آنذاك، اذ تبقى مسألة استخراج الابتحاه النظري ومنهج البحث عند باتيسـون هي مطلب يتقسـم بين سـؤال البحث واهميته واهدافه، والذي ركزنا فيه على مسألة التواصل الفرعي.

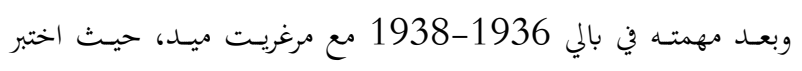

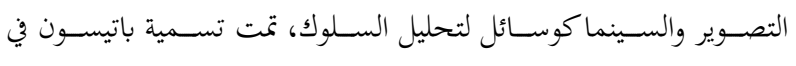

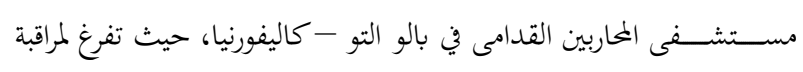
عائلات المصابين بالفصام، وقد اتاحت مقاربته المستوحاة من الانثروبولوجيا كما من علم التحكم الحركي ان يرى في المرض العقلي نتيجة خلل وظيفي

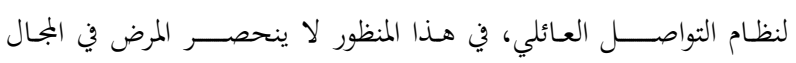

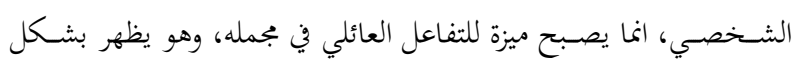
خاص كنتيجة لرباط مزدوج (Double Bind) معرف كتناقض لا يمكن

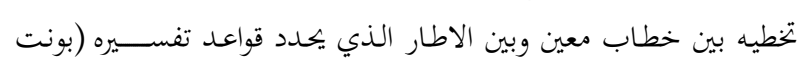
وايزار، 2006، صنطيه بين 273 273). وفي السياق ذاته، هناك ترجمات اخرى لمفهوم الرباط المزدوج لدى باتيسـون

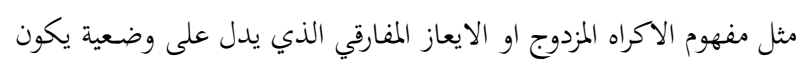

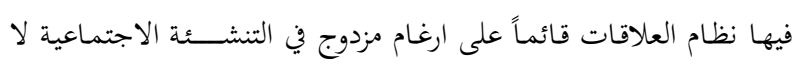

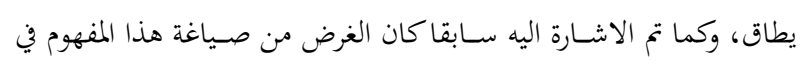
البداية يقتصر على دراسة مرضى انفصام الشخصية "الشيزوفرينيا"، ثم امتد

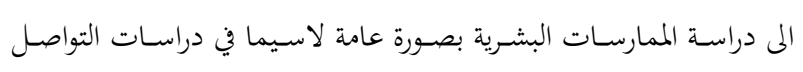

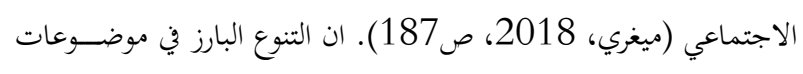

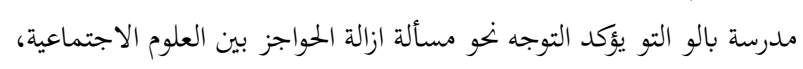
وتبني منهجية التداخل التكاملي الذي يســمح للباحث في الميدان الانتقال

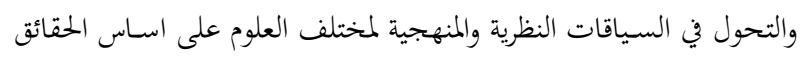

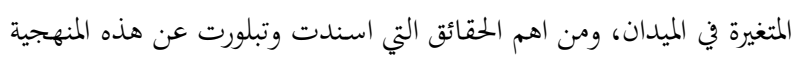

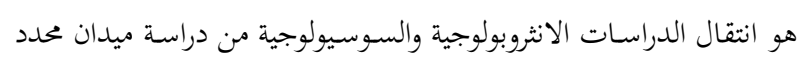

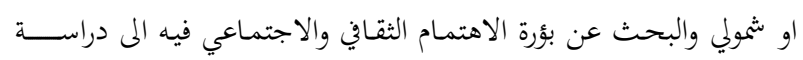


الاســلوب بين المجتمعـات (بونست وايزار، 2006، ص40)، من ثم

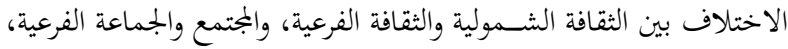

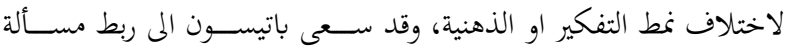

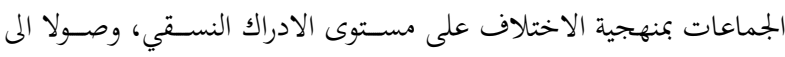
التقابل الجماعي. فالثقافة الفرعية هي نمط من المعيشة يختلف عن الثقافة الكلية، او بمعنى آخر

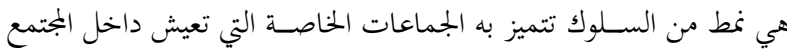

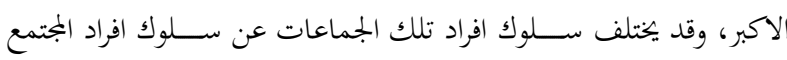

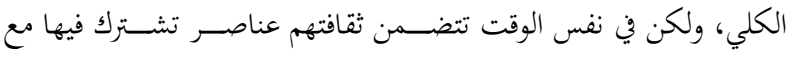

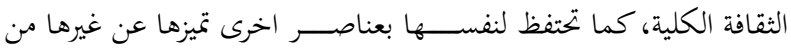

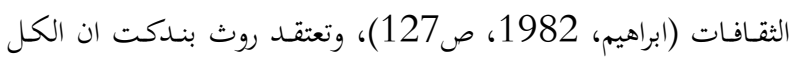

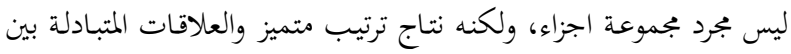

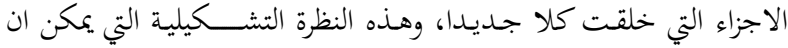

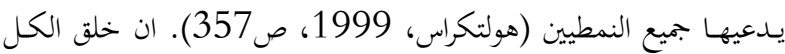

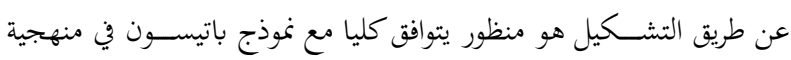

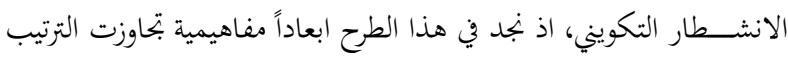
الهرمي للثقافة والترتيب النسقي للجماعة من خلال فهم اساليب الحياة على

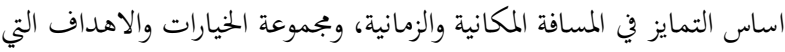

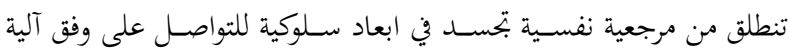
نمطية. ولا يقصـــ بالهرمية هنا القوة او الامر او السـلطة، بل تعني نظاما ناجما عن

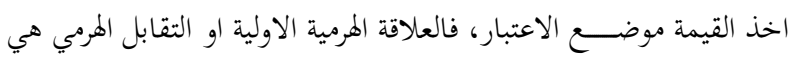

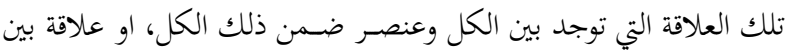
جزئين بالاشارة المرجعية الى الكل، ويككن تحليل هذه العلاقة ضسمن جانئن

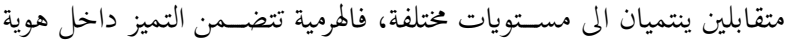

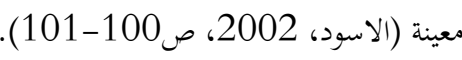
من جانب آخر يعرف علماء الانثروبولوجيا الجماعة الفرعية بوصـفهـا

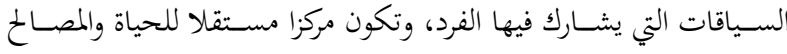
والسلوك البشري، وتتميز الجماعة الفرعية بوجود شعور فرعي مشترك وتمركز حول الســلالة، وكذلك الامن الداخلي والقانون والنظام والجهـد التعاويز (هولتكراس، 1999، ص172). ان اغلـب التوجهـات النظريسة في

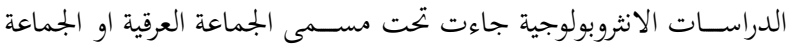
السلالية، بينما يميزها فريدريك بارث بالنقاط الآتية:

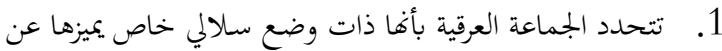

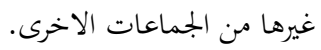

2. تحدد الجماعة العرقية من خلال اشـتراكها في محتوى ومضسمون الاخرى

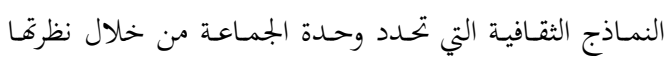
الإدراكية لهذا المحتوى الثقافي المتميز. 3. ان يكون لتلك الجماعة العرقية بناء خاص من وسائل الاتصال

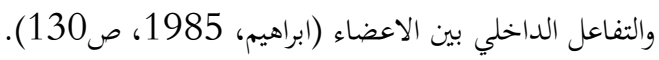

يُجدد التواصـل الفرعي في سـياق بجثنا والسـياق الاجتماعى والثقافي لميدان

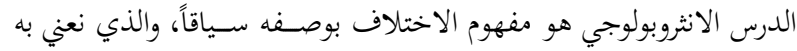

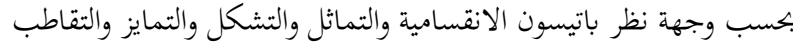

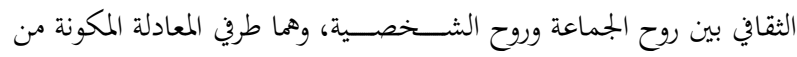

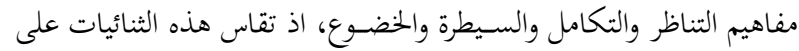
وفق فرضية باتيسون في الثقافة المشتركة والتشاركية، والتي هي عبارة عن بنية

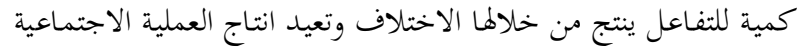
بصــورة متوالية ثقافية تبلور انماط ثقافية متناظرة ومتكاملة تعيد انتاج التطبع وروح الثقافة. وقد عرف باتيسون السياق بأنه "ظاهرة لا اساس لها ولا يمكن تحديدها في

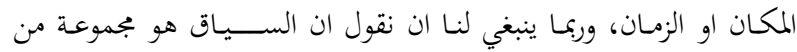
الاختلافات.. بل صورة عقلية او خريطة ذهنية، وهو اعتراف بالاختلافات التي تحدث فرقا ضمن مجموعة من العلاقات" (bale, 1992, p.16).

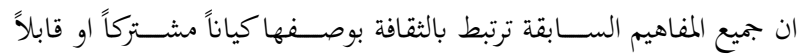

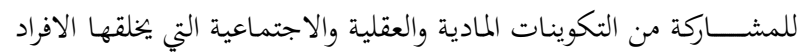

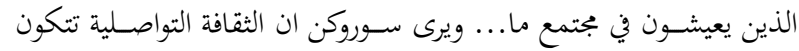
من ثلاث مستويات: المستوى الايديولوجي اي (المعاني، والقيم، والمعايير)،

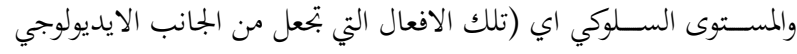

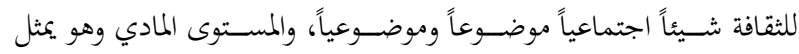
الوسائل الاخرى لاظهار الجانب الايديولوجي للثقافة وجعله شيئاً اجتماعياً

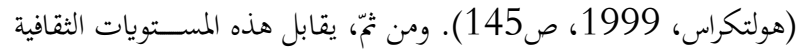
مستويات للتواصل وعلى النحو الآتي: 1. مستوى تشكل العلاقات والارتباطات التي يتم نسجها من

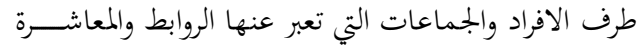

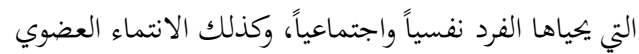
والوظيفي مجتمعيا ومؤسساتياً وتنظيمياً. 2. مســتوى اللغة واشــــال التبادل الرمزي من جهة التعبير والكلام والتخاطب. - ماط.

3. مستوى ارسال او نقل المعلومات والعمل على تصريفها آلياً

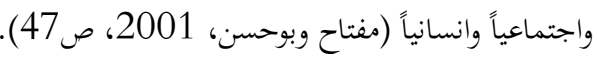
نلاحظ على الطرح الخاص بمستويات الثقافة والتواصل انه ذو طبيعة تصنيفية

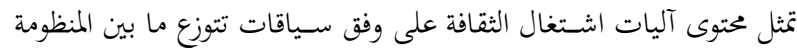

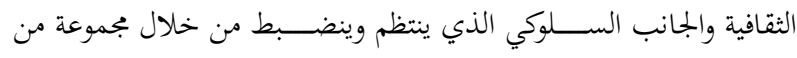

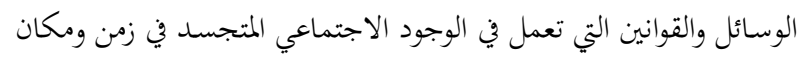
معلوم. ان ســـي الباحثين في بحال التواصــل الاجتماعي الثقافي للانثروبولوجيا

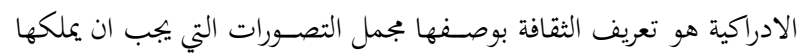
الفرد للتفكير والتصرف كعضو في جماعة، لذا يجب دراسة العمليات العقلية

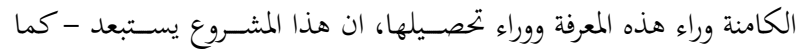

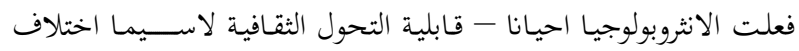


وانتظام تلك العلاقات ضمن تشكيلات تفرض هذه السمة التناظرية قاعدة منهجية مزدوجة لعملية التكامل لا يمكن النظر لاي عنصسـر ينتمي لمجموعة مبنية (كلية) بمعزل عن العناصسر الاخرى، ولا يمكن اعتبار ان مجموعة مبنية

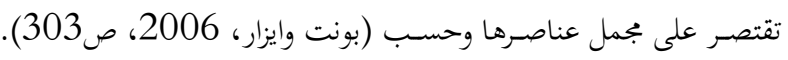

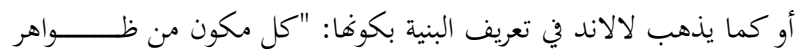

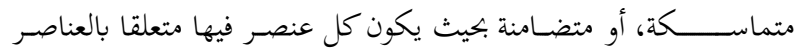

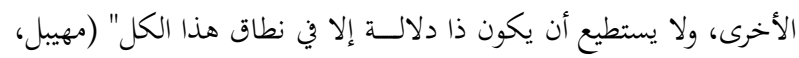

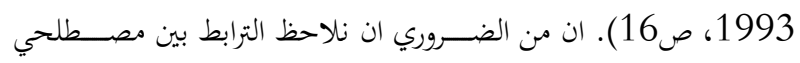

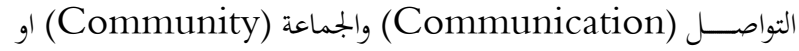
في اللغة العربية التواصــل والصــلة، والدور الذي يؤديه الاول في تشـكيل الثانية، اذ تكمن النقطة الجوهرية هنا في ان نعرف ان الجماعة ليسـت كيانا

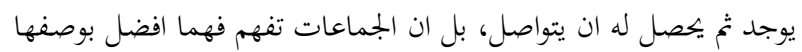

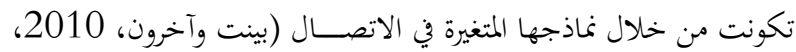
ص52). هذا التكون جرى فهمه والتأســيس له من خلال دراســـــات

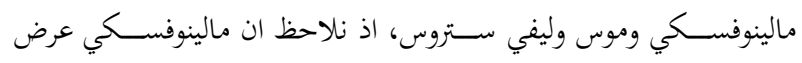
مفهومه الضمني عن السياق التواصلي للجماعة، او ما يعرف بسياق الحال، او اثنوجرافية الحقائق التبادلية للفرد والجماعة (التفاعل الاجتماعي) وهي لئي مكونة من اللغة والمكان والزمن الاثني المبني على ايديولوجية زمانية متشكلة،

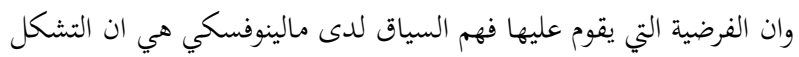

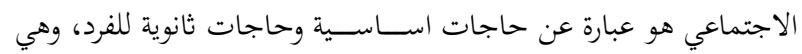

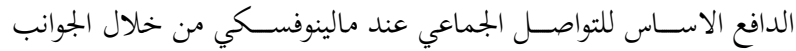
العضوية للفرد والثقافة داخل الجماعة، اذ يحتكم التواصل لسياق متغير بتغير

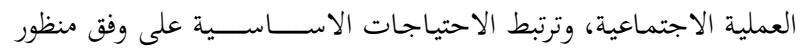

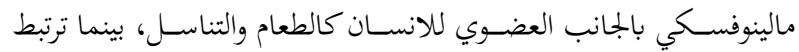

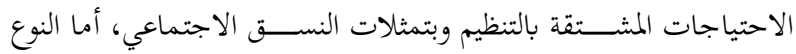
الثالث من الاحتياجات فيرتبط بالامن النفســي والانســــام او التوافق الاجتماعي والتي يمكن اشباعه عن طريق انساق المعرفة (اسماعيل، 1987،

من جانب آخر، فقد قدم الانثروبولوجسـت الفرنسي مارسـيل موس نظرية

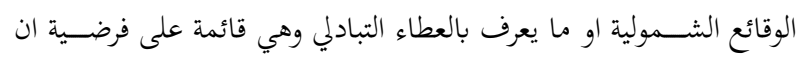

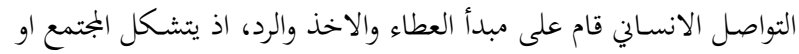
الجماعـة من خلالهـا، وتعيد انتـاج نفســــــا على وفق متطلبـات العمليـة

الاجتماعية.

وفي سـياق آخر، نجد ان توجهات ســتروس قائمة على توجه نظري يهتم

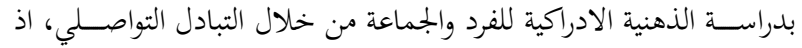
تتكون نظريته من تبـادل المنافع وتبـادل اللغة وتبـادل النســـــاء، وقد اهتم

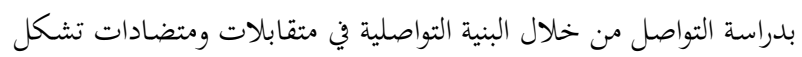

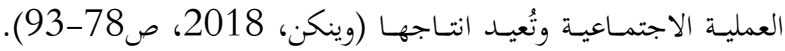
وبالموازاة مع الطروحات الانثروبولوجية الكلاســـيكية للتواصــلـ، يقدم لنا الانثروبولوجسـت راي بيردوسـتل تعريفا للتواصسل بابعاد منهجية حداثوية

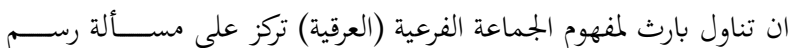

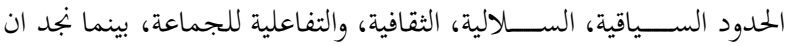
باتيسون بتحاوز مسألة الحدود الداخلية والخارجية للجماعة، وركز على مفهوم (التكوين الانشقاقي) اي التمايز التدريجي، اذ جاء تناول باتيسون للمفهوم بوصـفه آلية لفهم واسـتيعاب سـلوك الجماعات العرقية من خلال عملية التواصل الذي يحدد النمط الثقافي بالاضافة الى مرجعيات الجماعات (لبيب، 1999، ص15-16). وفي مقابل مفهوم الثقافة الفرعية والجماعة الفرعية بوصـفها آلية منهجية لفهم التواصـل، عرض باتيسـون مفهومين هما روح الجماعة Ethos وروح الشخصية Eidos، وثمة تمييز كامن بين المفهومين اللذين تتألف منها الثقافة معاً، وتشـير كلمة Eidos حسـب اسـتعمال

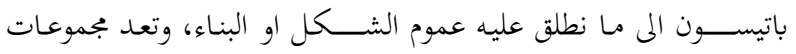
التقابلات الثنائية التي يصفها في دراسته للشخصية القومية نزعة المشاهدة

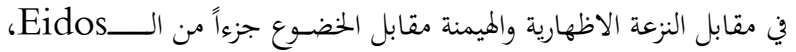

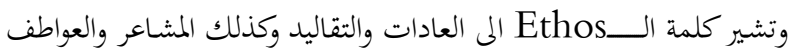
الجمعية المميزة لثقافة او حدث معين قد تم تعريفه وفقا للمعايير الثقافية، وتشـير الكلمة بصــورة اكثر تحديدا المى الطابع او الروح المميزة، وتبدو هذه فئه المفاهيم مترابطة وعلى الاقل في دراسته للشخصية القومية تعتمد روح الثقافة الــthos في تعريفها عبر الثقافي على العلاقة بين Eidos ثقافة معينة

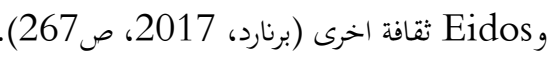
ان مفهوم روح الشـخصـية Eidos في نظر باتيسـون تعني التقنين الثقافي للجوانب الادراكية لشـصـية الافراد، ويقابل باتيسـون بين المفهوم ومفهوم روح المجتمع، ويعرف هذا المفهوم الاخير قائلا انه: نسق الابحاهات العاطفية

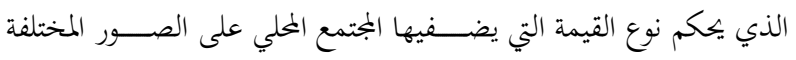
للإشـباع وعدم الاشـباع التي يمكن ان تعرض في بجرى سـياق الحياة، ومن الواضح ان هذا يعني تقسيما لنسق القيمة الى وجهة عاطفية واخرى فكرية

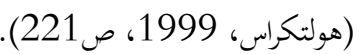
ولغرض تحقيق فهم ارجاعي لعملية التواصل الفرعي، وضع باتيسون مفهوم

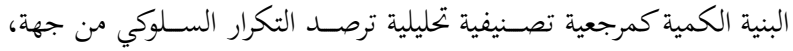
وعملية التناظر والتكامل والســيطرة والخضـــوع للتفاعل الاجتماعي للحياة

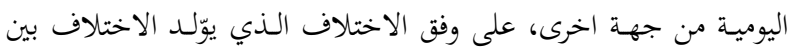

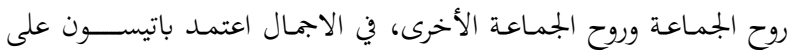

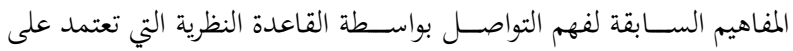

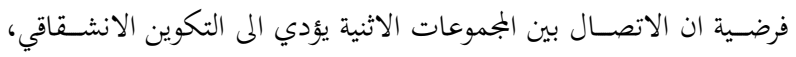
ولرصـد هذه الفرضسية يتوجب علينا تعريف البنية الكمية بوصففها التكرار السلوكي للادراكات المتجسدة في مجموعة معينة، اذ يقصد من اصطلاح الكم هو مســألة عدد المرات التي يتكرر فيها سـلوك معين في سـياق اجتماعي تحول الى موضـــوع اجتماعي منمط في جماعة معينة له قيمة ومعايير تنظمه وتضبطه. وفي السـياق ذاته، تكون البنية هي ما يعكس التحليل الداخلي للكلية، اي وجود عنصرين اسـاسيين في الاقل، ووجود علاقات ثابتة بين هذه العناصر 


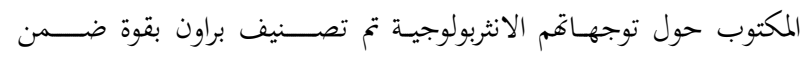

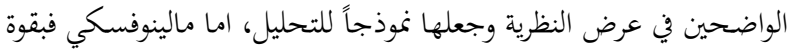
المنهج وقدرته على تحويل البعد النظري الى آليات اشــتغال ميدانية، اذ نجد

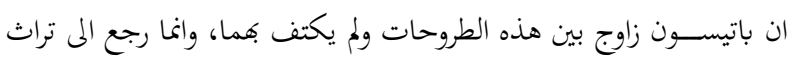

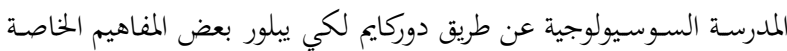
بدراسة المجتمع، وفي السياق ذاته، رجع الى المنظور الثقافي عند مالينوفسكي الم جذوره المتجسـدة في المدرسية الاميركية الثقافية لترصين توجهاته الميدانية وتطوير منهج المقارنة، وفهم عملية التثاقف.

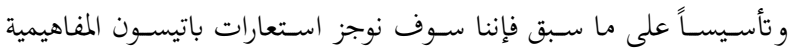
لمنهجه التكاملي بنقاط محددة: أ. استعار باتيسون بعض المفاهيم التطورية من توجهات السوسيولوجي بني

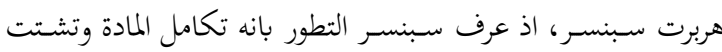
مصـاحب للحركة، حيث تتحول المادة من بتحانس غير محدد/ مفكك

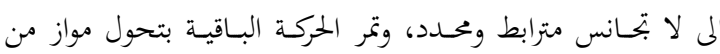
خلاله، ان المحور الاساس في نسق سبنسر هو الحركة وهي ليست قوة عمياء بل هي تخضـــع لقواعد محددة، ان مـا يترتب على القـاعدة

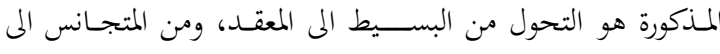
المختلف، بصــورة اخرى نتناول نظرية ســبنســـــــاثثة مفاهيم هي: (عدم استقرار التجانس، العزل، التوازن)، والرابط الاساس بين المفاهيم

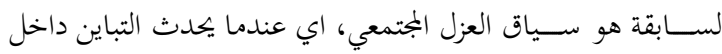
تجمع معين يتطور نوع من التخصـص في الاجزاء بالضـرورة، وهنا ثمة قاعدة، فالوحدات المتشــابهة تسـتجيب للمؤثرات على نحو متماثل، والوحدات غير المتشـابهة تسـتجيب للمؤثرات على نحو مختلف (حزة، 2015، ص75-76)، سـعى باتيسـون الى تفسـير المنظور السـابق

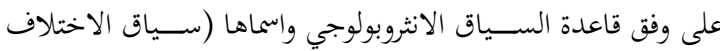
الذي يولد الاختلاف)، وسنوضح هذه القاعدة في مرحلة لاحقة من محاولتنا لبناء نظرية باتيسون في التواصل الفرعي الاثني، ونوجز هنا ان الاختلاف عند باتيسـون هو مفهوم سـياقي على شـكل متصـل بين التجانس واللا بحانس يحتوي على نقاط تكيفية نجملها بمفهوم التوازن.

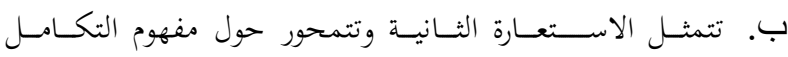
وهو المبدأ الذي بمقتضــــاه ترتبط الاجزاء مكونة (Integration) كلا واحدا، وهو يعني في الاثنولوجيا العلاقات الوظيفية بين العناصـر

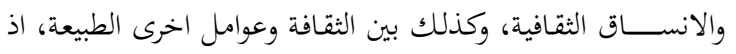

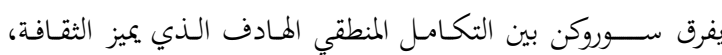
والتكامل العلي الوظيفي الذي يميز الانساق الاجتماعية... ولقد كان

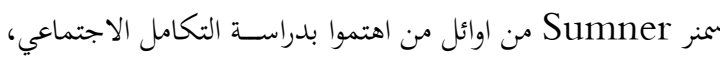
اذ يرى ان التكامل يعني التعادل الذي يخلق التوازن الاجتماعي الثقافي

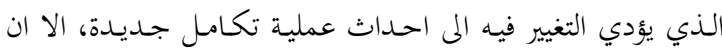

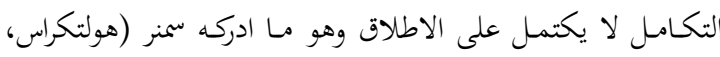

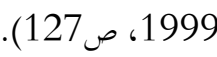

الطرح تعبّر عن ارتباط الثقافة بالبنية وارتباط التواصـل بالعلمية الاجتماعية، ويمكن رسم فرضية بيردوستل بصورة مبسطة: تواصل/مسار= ثقافة/بنية،

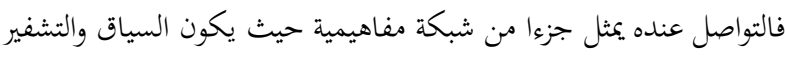
والبنية (النمط) والســيرورة قابلة للمبادلة كليا، ويمكن اســتخراج ثلاثة مئة مستويات تفكير بالاشتغال المنهجي حول التواصل:

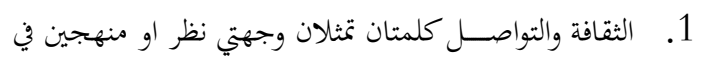
تمثيل التعالق الانســــاني (Interconnectedness)

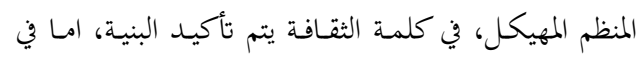

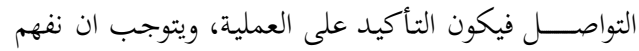

$$
\text { العملية على اساس بنية معينة. }
$$

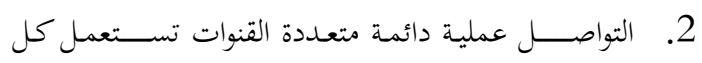

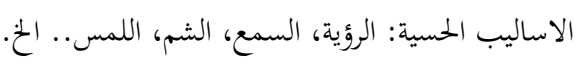

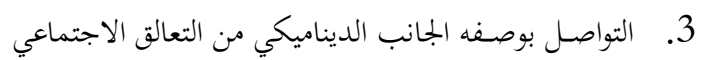
والثقافي.

المبحث الثاني: التوجه النظري لباتيسون (الانثروبولوجيا الاجتماعية الثقافية): مرجعيات التوجه النظري لباتيسون: تجســــــــوجهات باتيســــون النظرية المنهج التداخلي التكاملي في العلوم الاجتماعية الذي يقوم على اســاس تصـــيف المعطيات على وفق آليات اشتغال ميداني متنوعة، اذ يعمل النمط المعري التداخلي التكاملي على هيئة

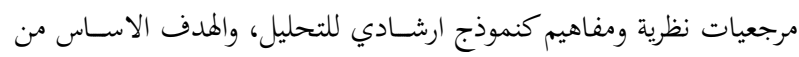

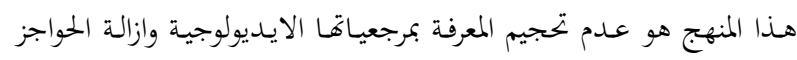
المصطنعة بين التخصصات والمدارس المتنوعة بتنوع الاشتغال الميداني. من اهم المرجعيات المعرفية التي كون من خلالها باتيسون نموذجه النظري هي التوجه الوظيفي البنائي بنسخته الكلاسيكية السوسيولوجية والانثربولوجية،

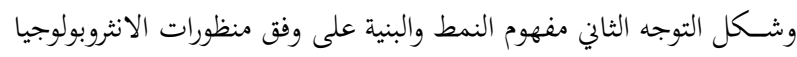
الثقافية (النفسية) او الثقافة والشخصية، ولغرض ازالة الحواجز المدرسية بين

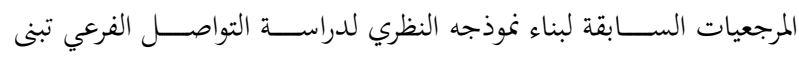

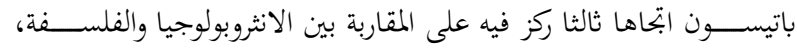
ونظرية السبرنطيقيا وتطبيقاهَا الاجتماعية الثقافية.

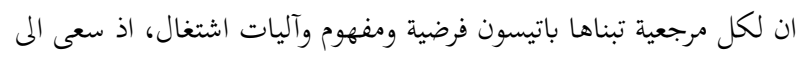

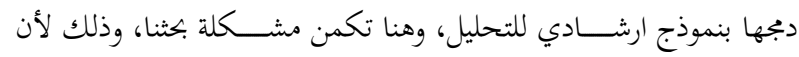

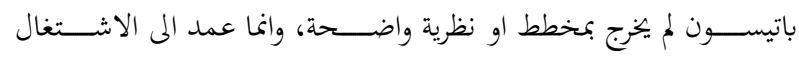

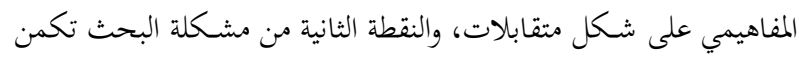
في عدم وضـوح اليات اشـتغال المنهج المقارن لدى باتيسـون في دراســاته التحليلية (يتيم، 2004، ص وص 168 وما بعدها)، وقد تحوّلت هذه المشكلة المبلة الى اشكالية في البحث الحالي.

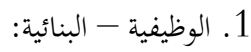

تتلمذ باتيسون في الاجواء المعرفية للمدرسة الانجليزية على يد كل من براون

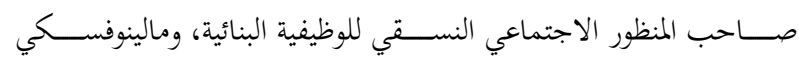

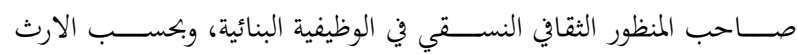


الكل ذاته، أو قل هو كل متكامل كل جزء فيه له مكانه ودوره ووظيفته التي

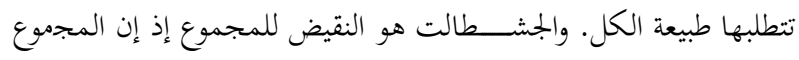

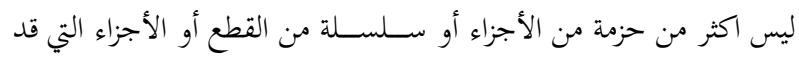

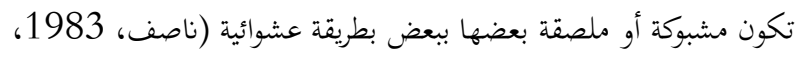
ص203-204). وقد استند باتيسون في بلورة توجهه النظري في دراسة التواصل الفرعي الى لى

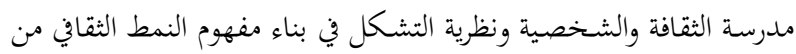

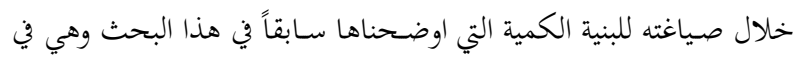

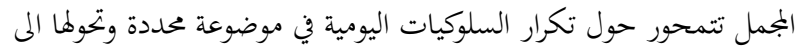
نمط متعارف عليه.

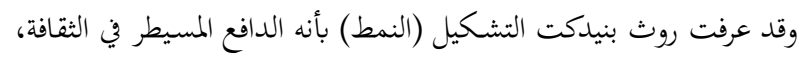

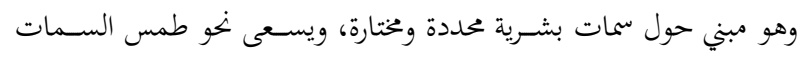

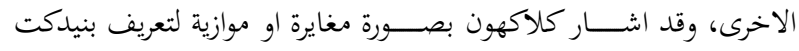

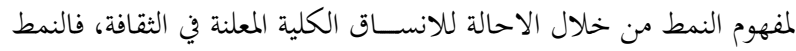

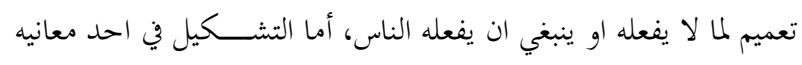

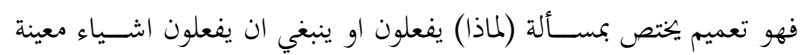

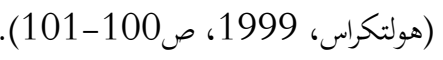
إن القضية الأساسية في النظرية الجشطلتية هي قضية الاهتمام بالتناقض بين

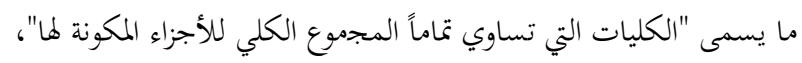

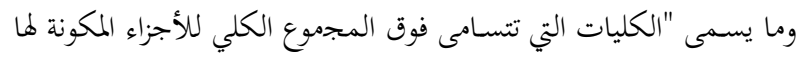

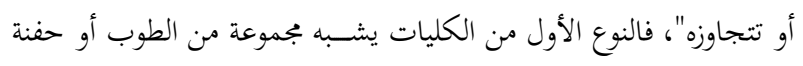

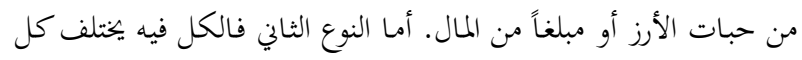

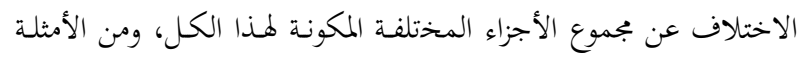

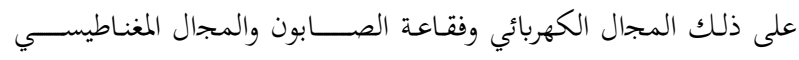

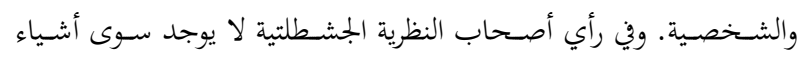

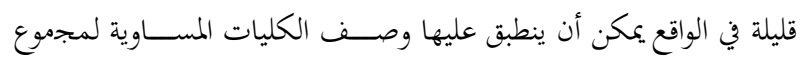

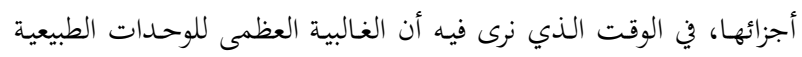

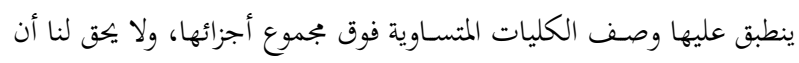

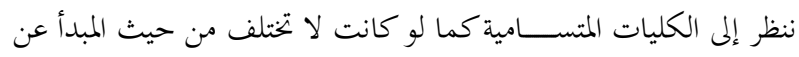

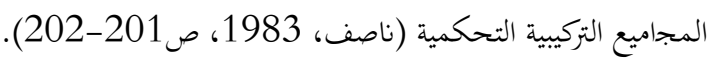

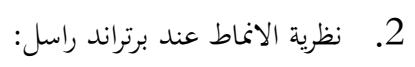

تأسسيسـاً على ما سـبق طرحه من تناول نظري يخص نشـوء وتبلور مدرسـة

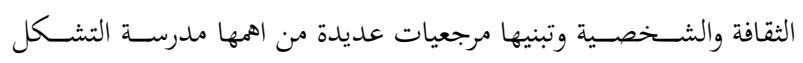

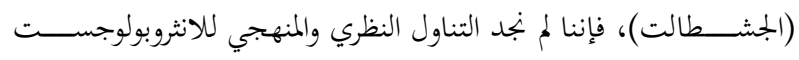

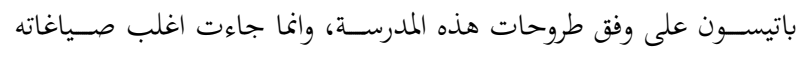

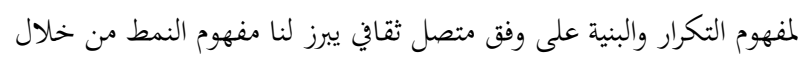

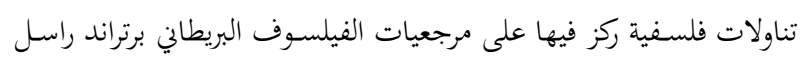
في بناء المتقابلات المنهجية لدراسة الجماعة الاثنية.

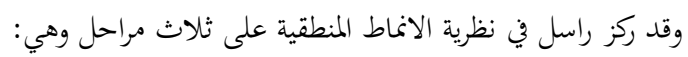

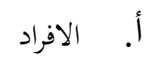

ومن وجهة نظر المدرسة الاميركية حاول كوهين Cohen ان يحل مشكلة التكامل غير التام وذلك عن طريق التمبيز بين التكامل الوظيفي او تنظيم التهائ

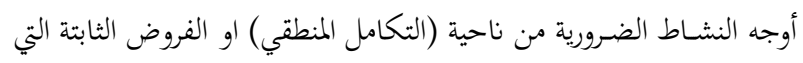

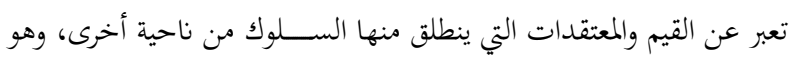

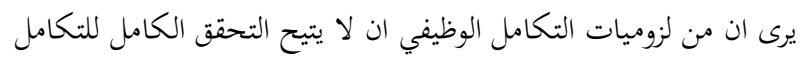

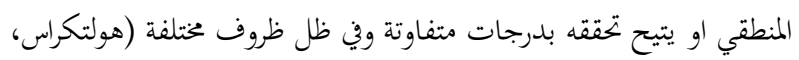

1999، ص128).

1. الجشطالت والانثروبولوجيا النفسية (الثقافة والشخصية):

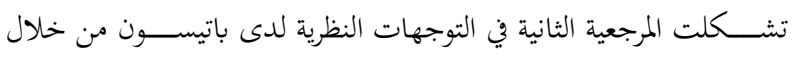

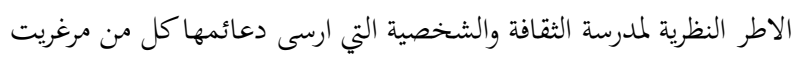

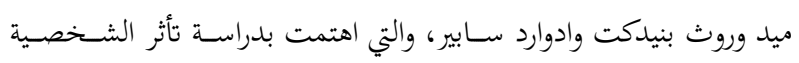

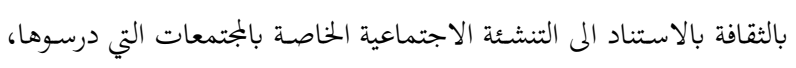

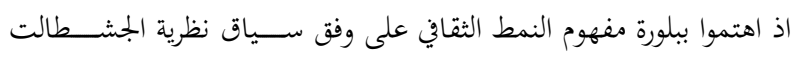

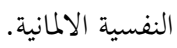
وقد ارتأوا ان امكانية فهم الادراك تتوقف على النظرة الى الشـــيء المدرك

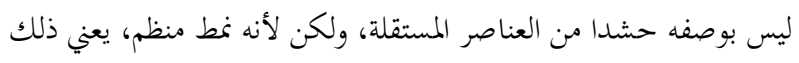

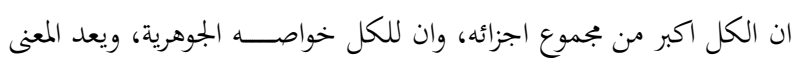

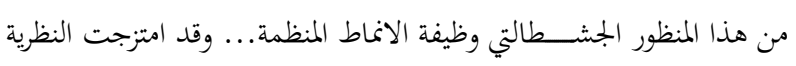

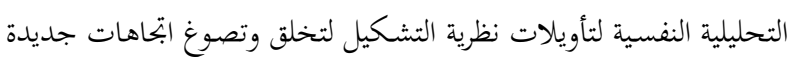

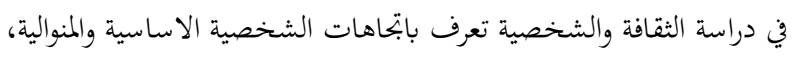

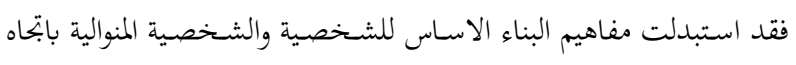

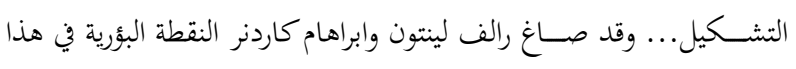

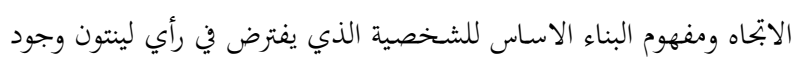

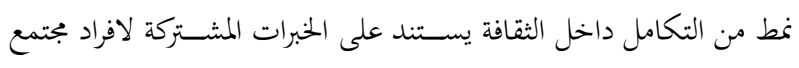

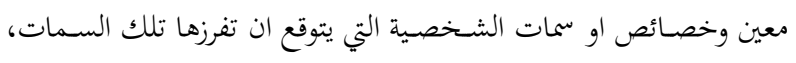

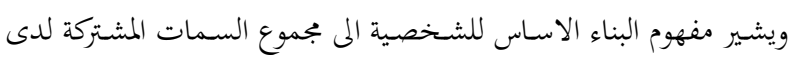

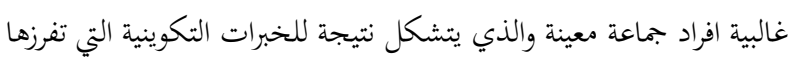

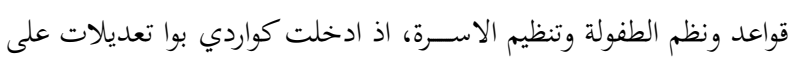

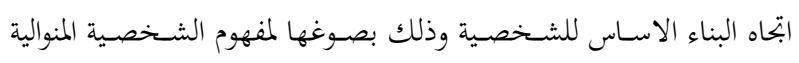

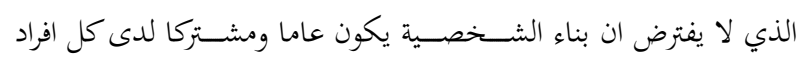

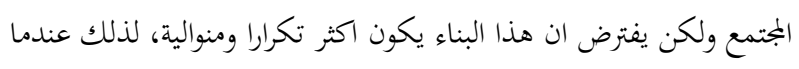

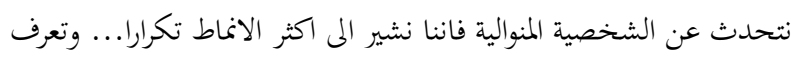

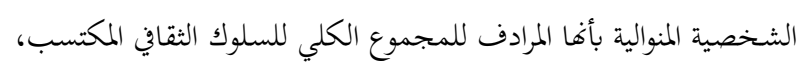

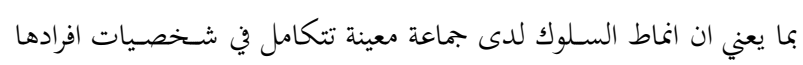

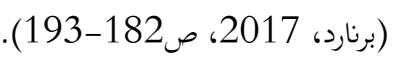

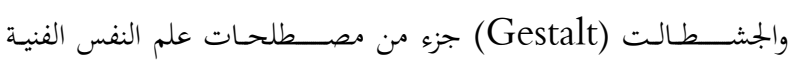

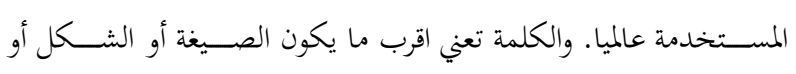

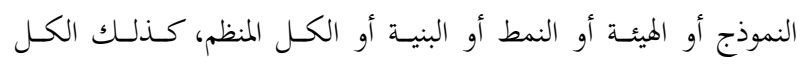

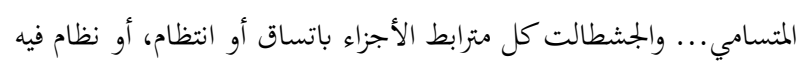

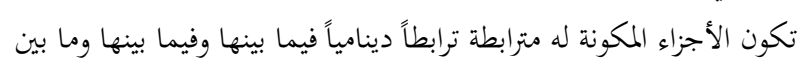


البريطانية، وقد حـاول رســــم مقـاربـة بين النمطية في المجتمعات البـدائية وتنشئتها الاجتماعية وبين النمطية الجماعية في المجتمعات الحديثة، وسنوضح طبيعة هذه النظرية والمنهج في ثنايا بحثنا هذا لاحقاً.

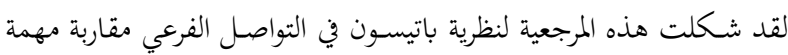
بين الثقافة بصــورةقا الثــمولية وتعدد الانماط باختلاف اثــكال العملية الاجتماعية، وأهم ما يميز ارتكان باتيسـون على نظرية راسـل التي حاول من خلالما وضـع منطق فلسـفي للمعادلات الرياضسية هو تقسيم الثقافة كنمط وتقسيم النمط كسمات ثقافية واجراء مقابلة بين الانماط المتعددة على وفق ولق قاعدة صـفات الصـفات اي سمات نمط معين تقابل السـمات ذامَا وتقابل سمات النمط الآخر.

$$
\text { 3. السبرنطقيا (بالي التو): }
$$

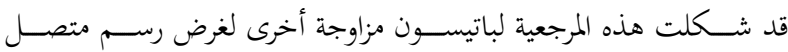

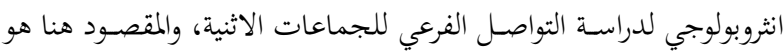

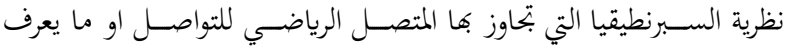

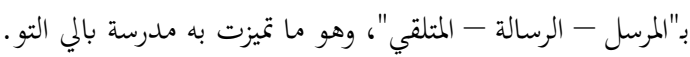

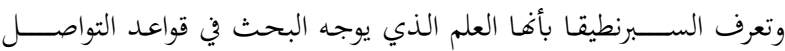

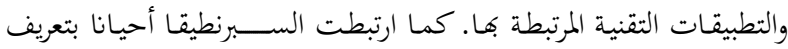
الذكاء وقياسه وشرح وظائف المخ وصناعة آلة التفكير. وتتطابق السبرنطيقا مع مشروع للمعرفة، يتمحور حول المراقبة الفعالة والتطبيق الناجح مما جعلها ذات جانب تقني أسـاسـا. يتحقق هذا التوجه من خلال التحكم في الطاقة المخركة للســلوك الفردي والجماعي حتى يتم توجيه شــتى الجوانب العقلية والنفسـية والعضــوية، بهدف الحفاظ على التوازن في المجتمع، وبهذه الطريقة

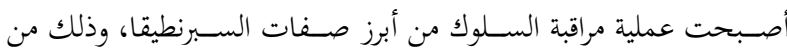

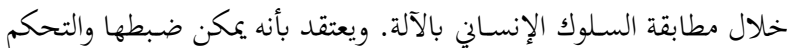
فيهـا ومراقبتها وتوجيهها. وبنـاء على التوظيف المنهجي الـدقيق للعلوم الرياضية، فإن أبحاث "فينر" وترصداته قادته نخو التطلع نهو الأخذ بالنموذج ولنج

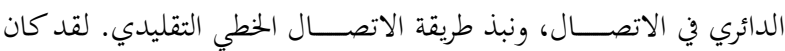

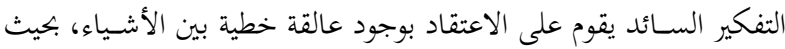
يؤدي السبب إلى ظهور النتيجة، لكن حصسيلة التفكير في العصسور الحديثة أدت إلى تبلور نوع جديد من العلاقات، يتمثل في "السببية الدورية"، القائم

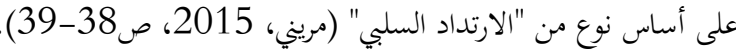
اذ نجد ان مرجعية باتيسون ومؤسسي مدرسة بالي التو قد استعاروا المفاهيم

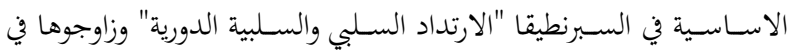

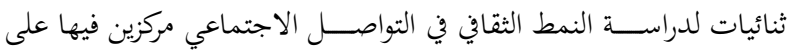
الادراك الفردي والارتدادات التي يولدها الفعل الاجتماعي داخل العلمية الاجتماعية، وسـوف نورد بالتفصيل تطوير باتيسون لهذه النظرية في توجهه النظري لدراسة التواصل لاحقاً. وبالرجوع إلى التناول التفاعلي (L’approche interactionniste)

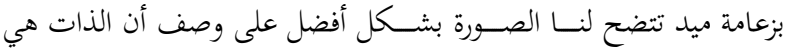
نتيجة للتفاعل الاجتماعي. وفي هذا السـياق يجب أن لا نغفل الدعم الذي
ب. ب. ب الصفات

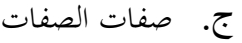

ويعد تقسيم راسـل للأنماط كرتب تتعدد على وفق المتبنيات النظرية للنمط،

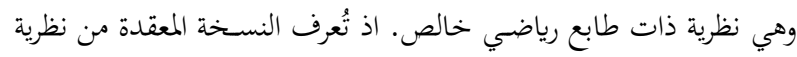

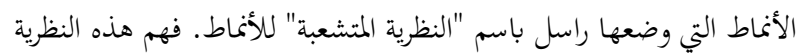
فهمًا صحيحًا من الأمور الخلافية، ولكن الوصف التالي قد يقدِّم تقريبًا أولٍِّا كان السبب الذي دفع راسل إلى ابتكار 》التشعببه ويُقصـد به التقسيم

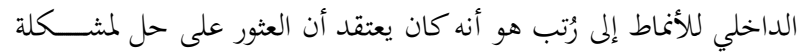
التناقض الظاهري كان يتطلب ذلك بالتحديد. وكان تصـــوره أن مشـــكلة التناقض الظاهري تنشأ من محاولة تعريف الصفات باستخدام تعبيرات جبرية

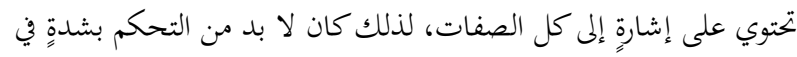

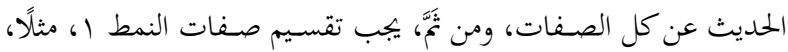
تقســيمًا فرعيّا إلى رُتب: رتبة أولى من الصــفـات لا يرد في تعريفها التعبير الجبري 》كل الصــفاتها، ورتبة ثانية من الصــفات يرد في تعريفها التعبير

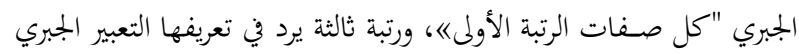

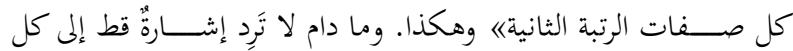

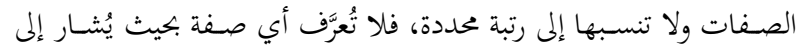

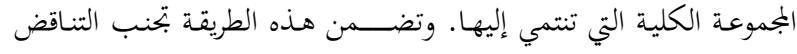

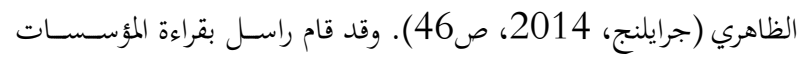

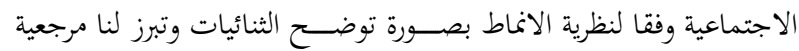
باتيسون لراسل، ومحاولة قراءة الاخير للجماعات الاثنية على وفق التقابلات النمطية. فقد دعا راسل الى تغيير المؤسسات الاجتماعية تحقيقا لاحترام الفرد وتنمية لدوافعه الخلاقة، ويقول راسل: ان الشيء المهم هو ضرورة تغيير مؤسساتنا

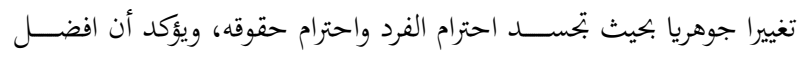

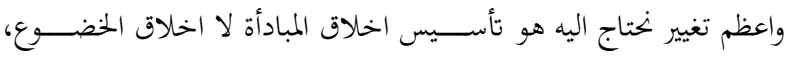
اخلاق الامل لا اخلاق الخوف، ويضــيف: ما نحتاج اليه هو الحياة الفردية

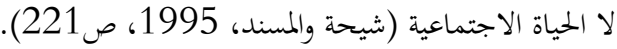
أما الحجة التاريخية التي قدمها راســل للتدليل على صــحة ما يذهب اليه

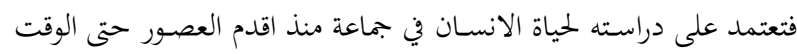
الحاضــر، ففي المجتمعات البدائية كانت المســـايرة والخضـــوع للجماعة من الشروط الضرورية لتحقيق الامن، وكان التشابه بين اعضاء الجماعة ضروريا لراحة الفرد واشــباع حاجات الجماعة، وبالتالي كان التنظيم الاجتماعي قوة تســتبعـد الاختلافـات الفرديـة وتؤكـــ الوعي الجمعي، ومع تقـدم الحيـاة

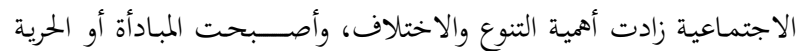

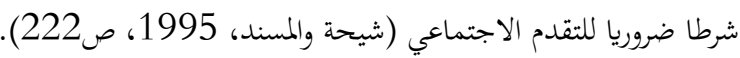
وقد وظف باتيســـون مقاربة راســل للبعد التاريخي في رســـم معالم جديدة

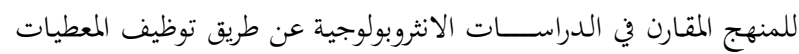
الاثنوجرافية التي استحصل عليها من دراسته لمجتمع النافن (الطقس والشكل الاجتماعي) كما ذكرنا ســـابقا بإجراء مقارنة بين الثقافة الاميركية والثقافة 
ان محتوى التقابلات في هذه الثنائيات هو محتوى يبرز التناول الثقافي في

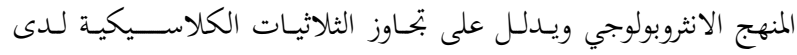
التأسـيسـات الرائدة في الانثروبولوجيا كثلاثية مارسـيل موس وثلاثئية كلود ليفي ســتروس، هذا التدليل قد جرى تطويره بشـــكل اكثر ارتباطا بالعلوم

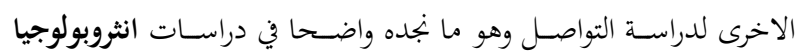
الفرجة التي تركز على ثنائية المضامين بين سياق المنتج من قبل الممثلين على

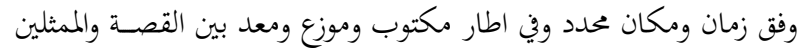

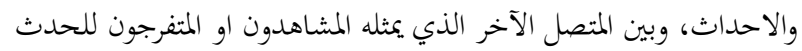

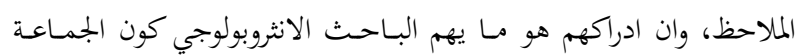

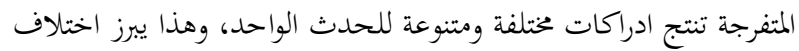
المرجعية الثقافية والجماعية والتنشـــئة الاجتماعية لكل فرد على الرغم من كوغم يشكلون جماعة واحدة.

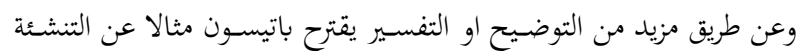
الاجتماعية في المجتمع الاميركي والمجتمع البريطاني، ففي انجلترا وجد ان الاب

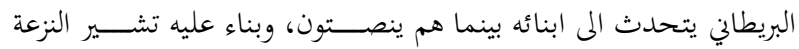

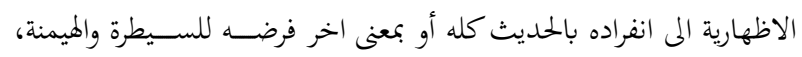
فيما تشـير نزعة المشـاهدة الى الاصـغاء، أما في اميركا فان نقيض ذلك هو

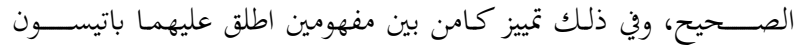

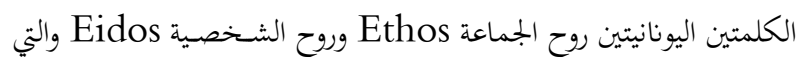

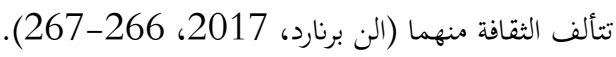
و تأسيسا على هذه المنهجية المقارنة التي طورها باتيسون على وفق المعطيات

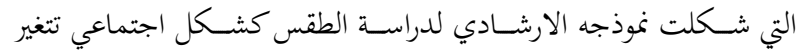

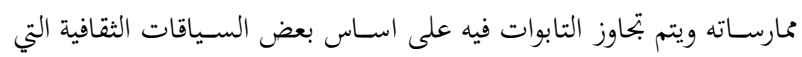

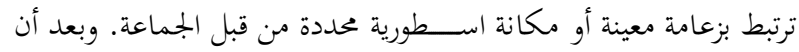
طور باتيسون ابعادا اثنولوجية للتحليل والمقارنة وتم تطبيق هذا النموذج على بلى بلى

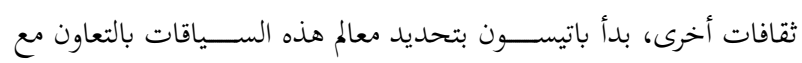

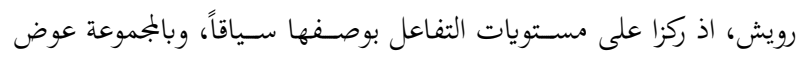
الاهتمام بالمستويات البيشخصية والثقافية. وقد تصور باتيسون النموذج السابق من المفاهيم الخاصة بروح الجماعة وروح

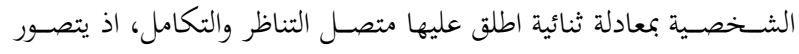
باتيسون دائما التفاعل بين الاشخاص او بين المجموعات كمقطع وكمتتالية من ردود الافعال تترتب عن ردود افعال على ردود الافعال، وهكذا يميز بين نظامين اســـــــين من العلاقات، علاقات تناظرية يدخل من خلالها

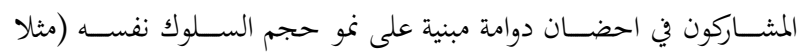
العنف)، وعلى علاقات تكاملية التي يكون خلالما المشــــاركون كياناً ثنائي القطب (الحماية والضــف، السـلطة والخضــوع، حب الظهور واســتراق

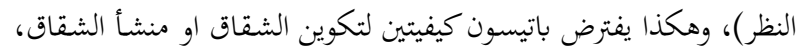

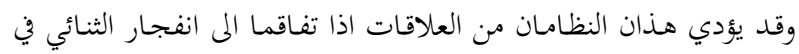
حالة الافراد، والنظام الاجتماعي في حالة المجموعات، ويقترح باتيســـون
قدمه المنظور النسقي بزعامة باتسون (Bateson) من مدرسة بالو التــــو

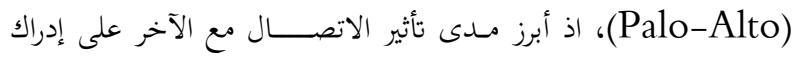

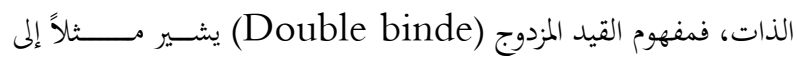
الرسائل المتناقضة التي قد تُولد اضطرابا شاملا على مستوى الهوية (كركوش، 2014، صن 275). وعليه، نبرر أن السـبرنطيقا عبارة عن جهد لفهم الاسـس التقنية للاتصـال البشري، بيد ان هذا الاتصال يتكون من ثقافة، وصمت، وإيماءات، وترانيم

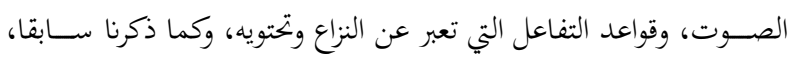
لعبت الانثروبولوجيا دورا في تجاوز التصـــورات الخطية للاتصــــال بالتركيز

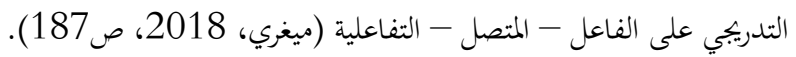
وأن أول ترجمة او فهم للسبرنطيقا عند باتيسون بحسـدت في مفهومه "القيد المزدوج" و "الاتصال المتناقض"، فالأمر : "كن عفوياً" يلغي مضمون الرسالة،

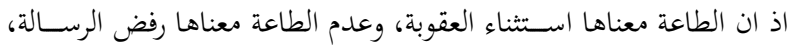

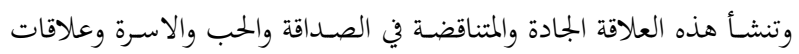

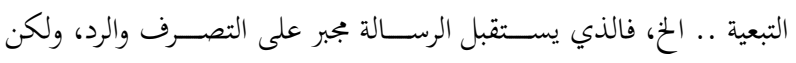

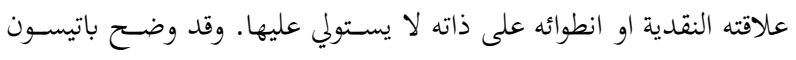

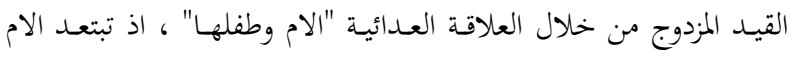

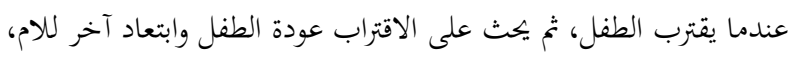

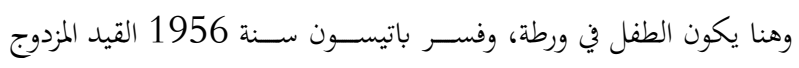

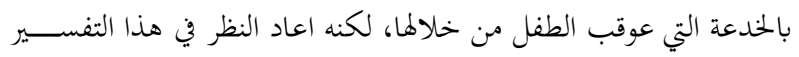

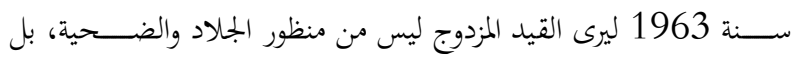

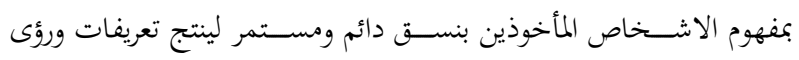

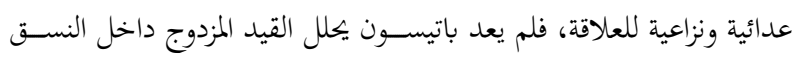
الاســري وانما النسـق الاســري داخل القيد المزدوج (ســـدي، 2013،

المبحث الثالث: منهجية باتيسون في التواصل الفرعي:

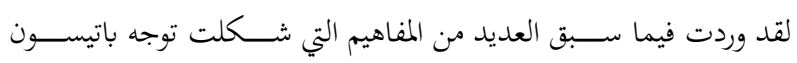
المنهجي في دراسته للتواصل الفرعي، ومن ابرزها التكامل والتناظر، والسيطرة

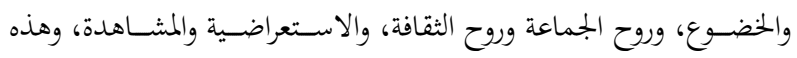

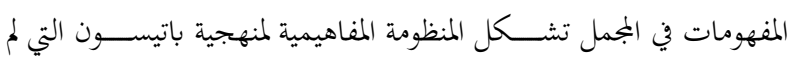
تتضــح معالم نموذجها النظري واليات اشـتغالها المنهجي، ونسـعى الى بيان واستخلاص النظرية والمنهج لدى باتيسون في نهاية هذا المبحث. ترتكز منهجية باتيسون على مجموعتين من التقابلات او التعارضات الثنائية:

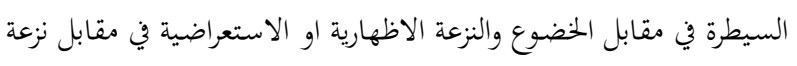
المشاهدة، اذ يقول باتيسون: ان ثنائية التعارض - السيطرة مقابل الخضوع إنهو ترتبط ارتباطا واضسحا بالابوة (السـيطرة) والطفولة (الخضـوع)، بينما تكون ثنائية التعارض النزعة الاظهارية او الاسـتعراضـية في مقابل نزعة المشـاهدة متغايرة في الطريقة التي تطابق بها او تمثل الســيطرة والخضـــــع (برنارد،

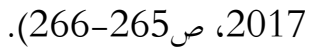


وعلى اسـاس الترسـيمة السـابقة التي تناولت وضــع المفاهيم المنهجية التي

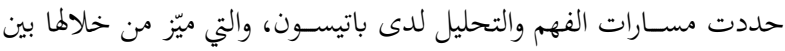
نوعين من العلاقات في مســــار المنظور التفاعلي هما العلاقات التكميلية التئية

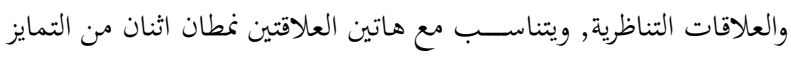

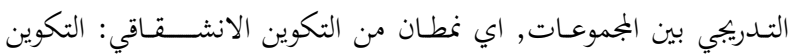

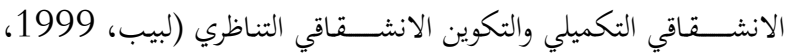

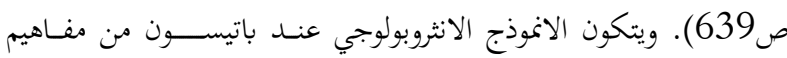
متعددة أبرزها: 1. المنظور التفاعلي: وهو المنظور الذي يحدد رؤى وتصورات الافراد بحاه

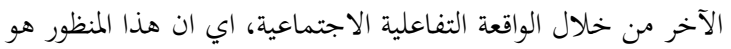
منطلق ترتســم من خلاله وجهات نظر التكامل والتناظر الذي يبرز استمرار عملية التواصل او انتهائها.

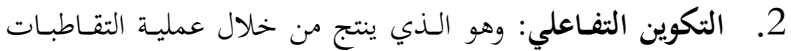

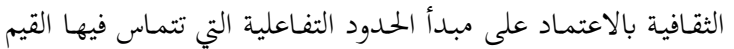
والعادات لتحتكم اليها افعال ومشروعية هذه الافعال بين الجماعات.

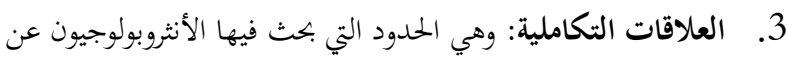

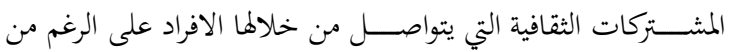
اختلاف مرجعياقم الجماعية. 4. العلاقات التناظرية: يقوم على التماثل في الصــفـات المشـــركة للمرجعيات الثقافية على الرغم من وجود العديد من التباينات. وهذا الفهم لنموذج باتيســـون يؤكد مدى اختلافه عن البنائية الوظيفية من

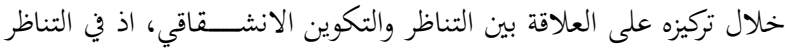

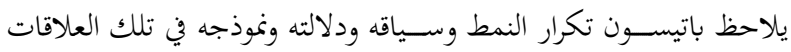
الاثنية واداء الطقس عند جماعة النافين، بينما اهتمت البنائية الوظيفية بفهم

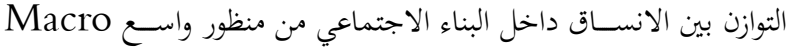

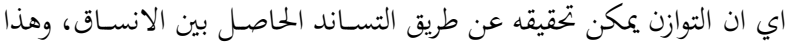

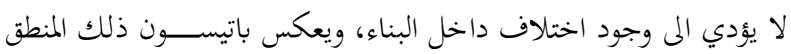
بسـؤاله المنهجي كيف يؤدي الاختلاف الى اختلاف، ومن ثم الى اسـتقرار

وقد اتبع باتيسون منهجية تكاملية تمت الاشـارة اليها في مبحث المرجعيات النظرية الخاصة به، اذ تحدد بالخطوات الآتية: 1. تحديد الشـكل: اذ ارتبط هذا الجانب بنظرية الجشـطالت ذات البعد البها

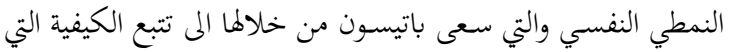

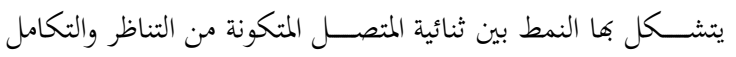
بالاستناد الى روح الجماعة (السلم القيمي). 2. ملاحظة التكرارات: والتي اختص وقصد بها باتيسون متابعة السلوك

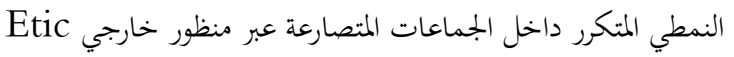

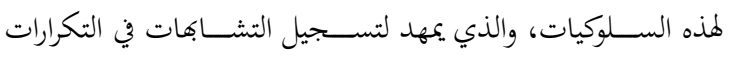

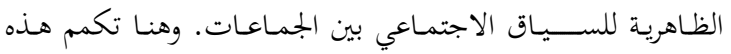

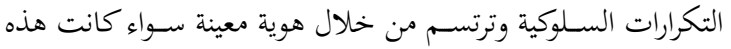

كيفيات ســبرنطيقية عدة تمكن النظام من الاحتفاظ باسـتقراره وتوازنه

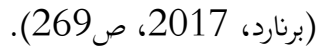
ولغرض صــناعة آليات اشـتغال ميدانية لهذا التوجه النظري بين المتناظر

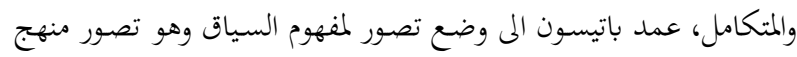
عمل ميداني واسماه "سياق الاختلاف الذي يوّلد الاختلاف"، اي أن فكرة باتيسون مفادها ان الملاحظ جزء من النظام الذي يدرسه. وغالباً ما يعطي

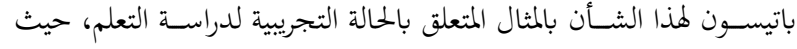
يصف عالم النفس ذاته خارجاً عن بجموعة العناصر الفاعلة في التكيف، اذ اذلئل

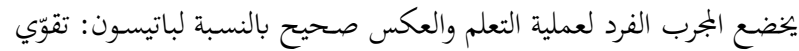

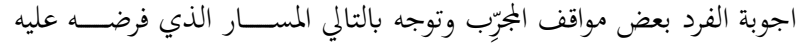

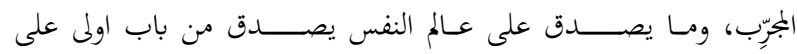

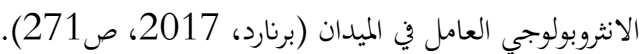
وما ســـق طرحه جرى تصـــيفه تحت مفاهيم عدة منها الانثروبولوجيا الانعكاسية والنماذج المولدة والنصوص المستخلصة والانثروبولوجيا الحوارية،

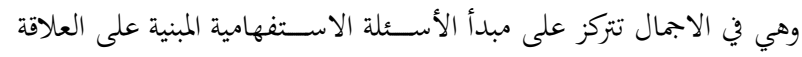

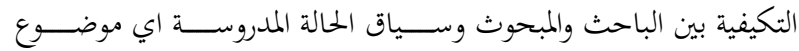

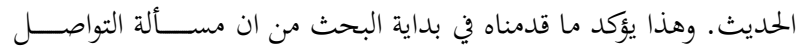
الفرعي هي من اولى المشكلات التي واجهت الباحث الانثروبولوجي العامل

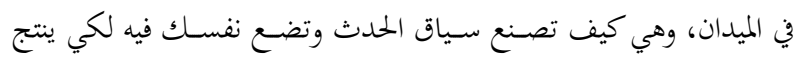
معاني تساعد في فهم مجريات الحياة الاجتماعية. وقد حاول العديد من الباحثين بتميع مفاهيم باتيســـــن النظرية بخطاطة

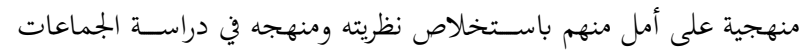

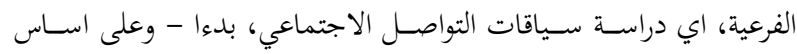

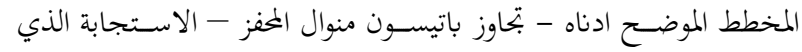

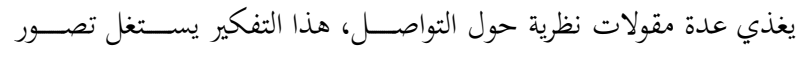
السياق كما يلاحظ باتيسون نفسه، فهو دائما قادر على التمعن في صورته

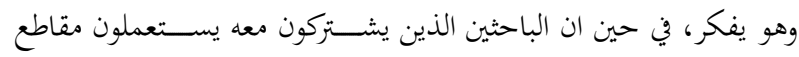

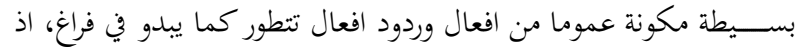

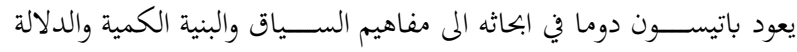
(امطوش، 2013، ص55)، وقد قدمنا الى هذه المفاهيم في ثنايا هذا

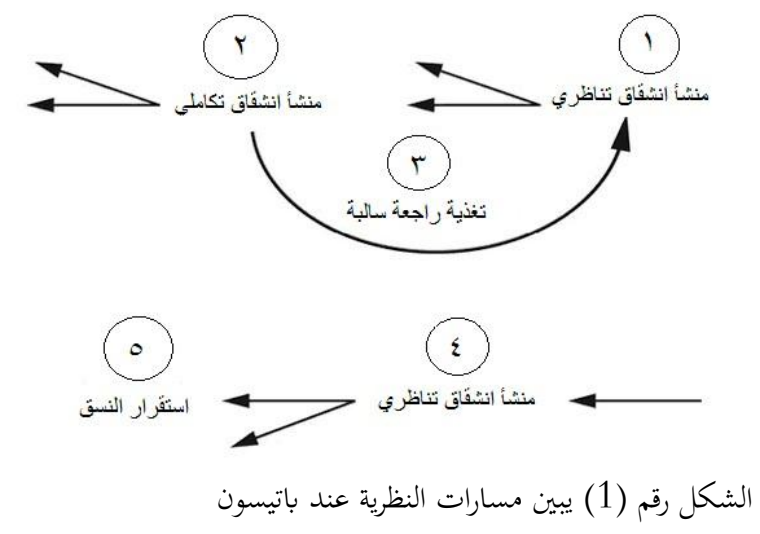


تبنى على اسـاس النموذج الارجاعي في مديات التكوين الانشـقاقي، ويعني

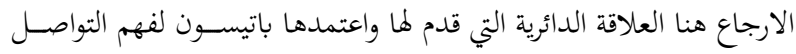

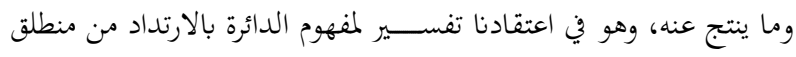
تنتهي به نقطة التفاعل. ونرى ان مفهوم العلاقة الدائرية يتوجب ان يؤخذ بمديات فهم اخرى ترتكز

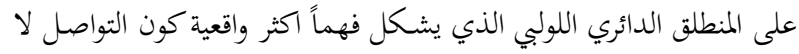

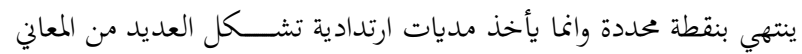

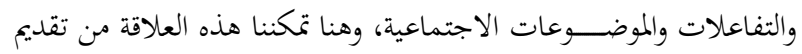
تعريف لمفهوم التكوين الانشقاقي بوصفه السلوكيات الخمّلة بقيمها واعرافها

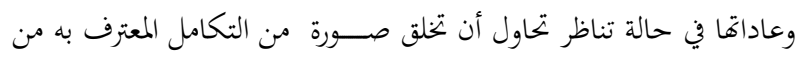

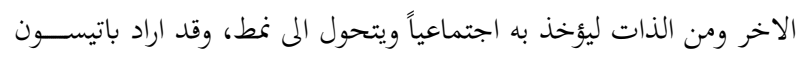

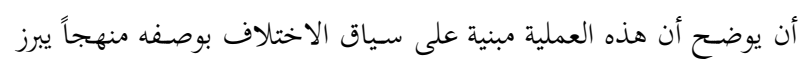

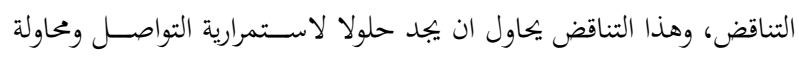
العودة الى حفظ توازن النسق الاجتماعي.

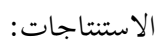

يشكل موضوع التواصل الفرعي لدى الانثروبولوجست جرجوري باتيسون

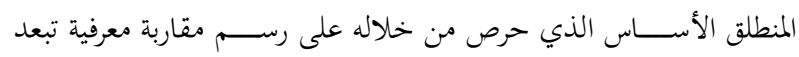

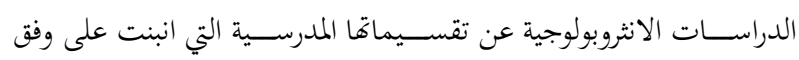

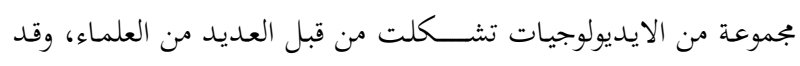

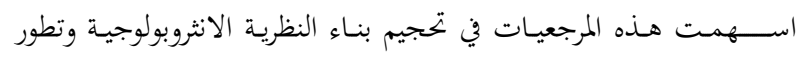

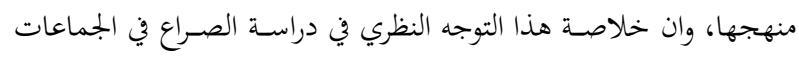

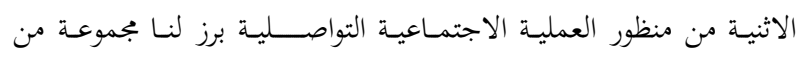

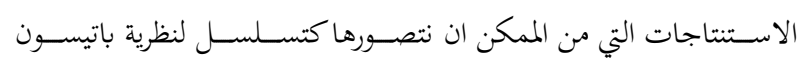
ومنهجه، والتي يككن اجمالها بالآتي:

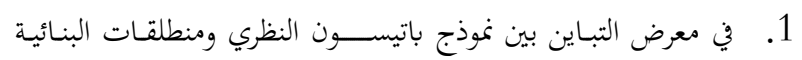

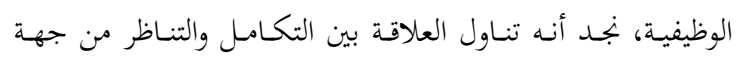

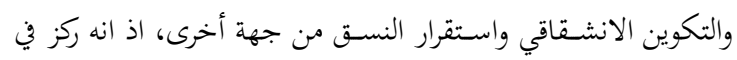

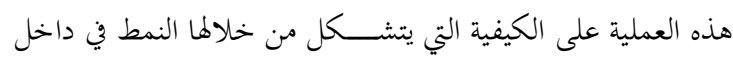
الصراع بصورة متوازية بين روح الشخصية وروح الجماعة، وهذا التوازي لئيل

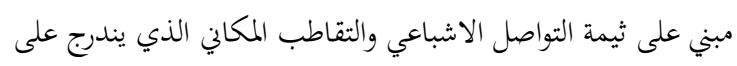

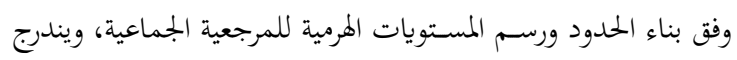

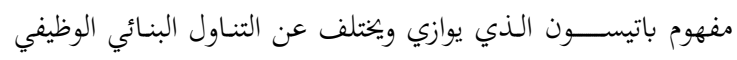

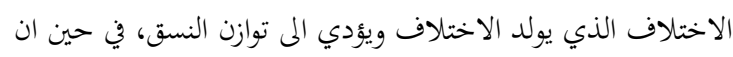

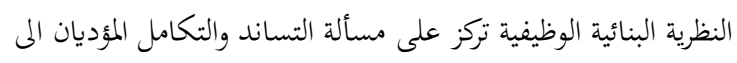

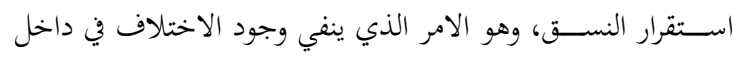

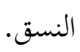
2. اعتمد التوجه النظري عند باتيسـون في التواصل الفرعي على مجموعة

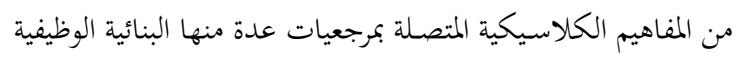

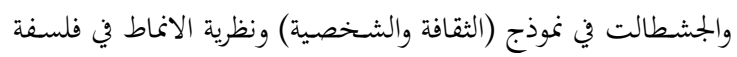

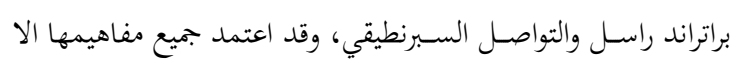

الهوية صراعا طائفيا او اثنيا او نمطا حياتيا استهلاكيا، وحتى صراعا في التنشئة الاجتماعية داخل الاسرة الواحدة. 3. المقارنة بين النكرارات: وهي في الاجمال تتمحور حول بناء الافكار

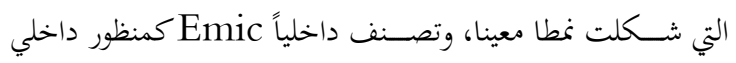
لنسـق الافراد او لروح الجماعة الذي تشكل معلى مرجعياتم الايديولوجية.

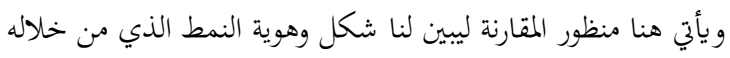
يشتغل سياق الاختلاف ليولد التوازن والاستقرار.

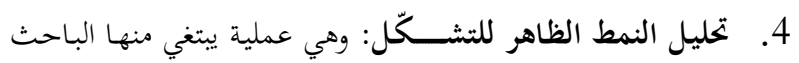

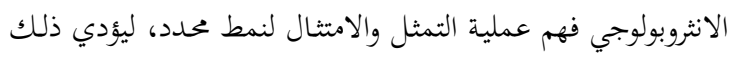
بنا الم فهم العملية الاجتماعية بمجملها. ويمكننا أن نجمل فهمنا لنظرية باتيسون ومنهجه بالشكل الآتي:

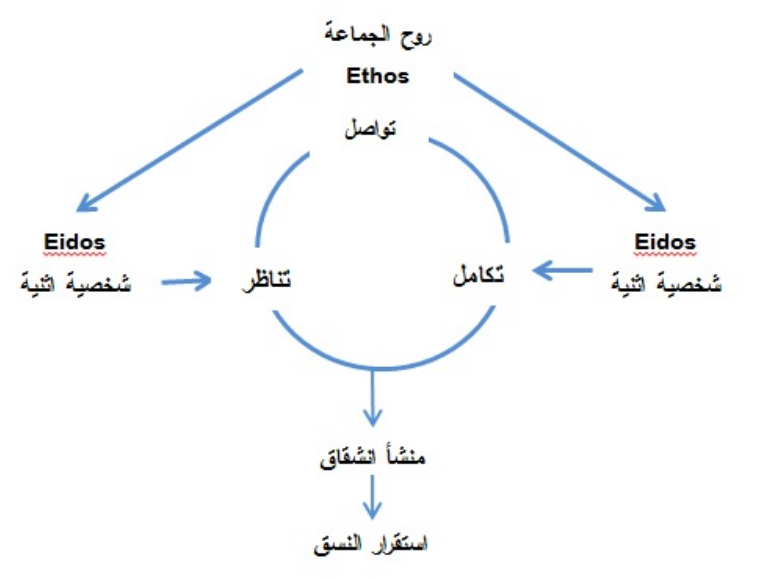

الشكل رقم (2) يبين النموذج الارشادي لعمل باتيسون النظري

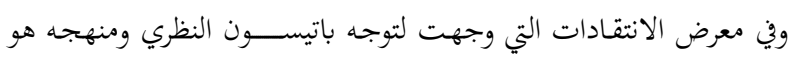

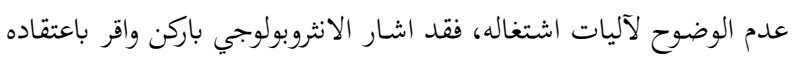

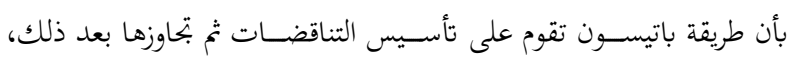

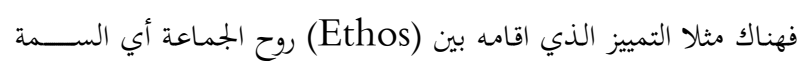

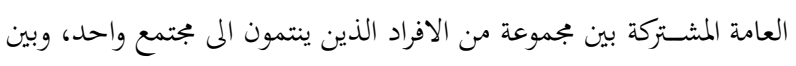

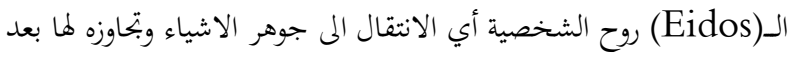

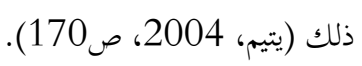

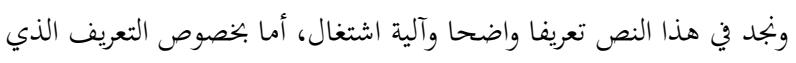

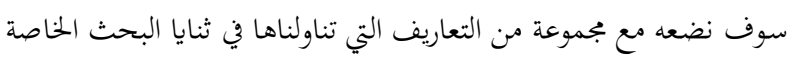

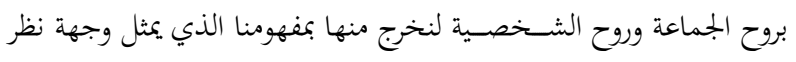

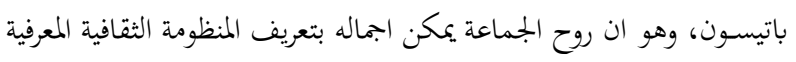

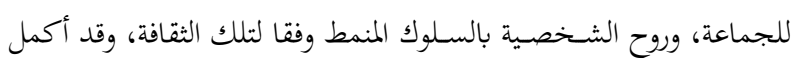

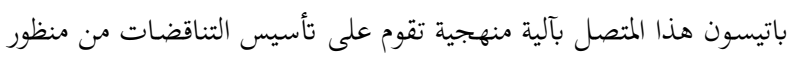

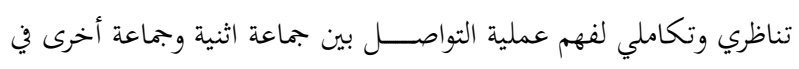

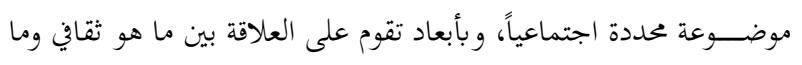

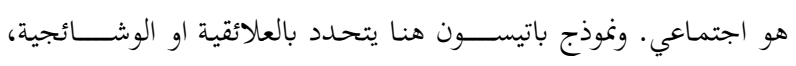

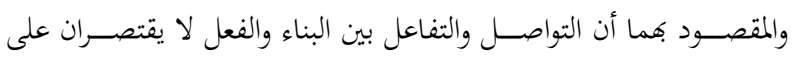

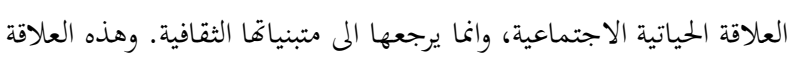


دراسـته للتنشـئة الاجتماعية، الا انه اهتم بعملية بناء النمط النفسـية والثقافية والاجتماعية، ويعدّ الباحث الانثروبولوجي الاول الذي ربط بله بين مسألة بناء النمط وتغيره بمسألة الصراع.

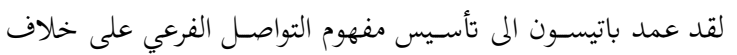

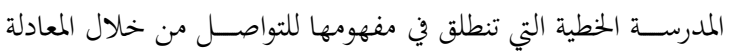

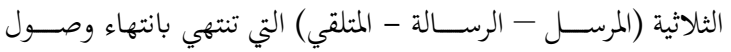
الرسالة وادراكها من قبل الطرف الثالث، بينما ركز باتيسون في تناوله بـانهي

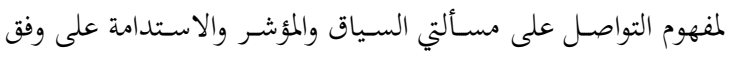

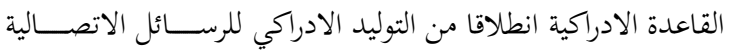
بمنظور ارجـاعي Feedback ذي سمة توليديـة تعتمد على قياس تكرارات في سلوكيات معينة بحسد انماطا محددة تتواصل داخل جماعة واحدة وبين جماعة أخرى.

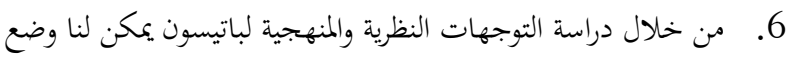
تعريف لواحد من اهم اركان نظريته وهو البنية الكمية التي تعبر عن

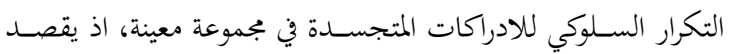
من اصطلاح الكم هو مسألة عدد المرات التي تكرر فيها سلوك معين في سياق اجتماعي تحوّل الى موضوع اجتماعي منمّط في جماعة معينة له قيمة ومعايير تنظمه وتضبطه. المصادر حسب ورودها في متن البحث:

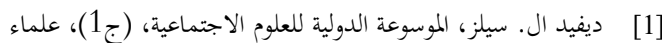

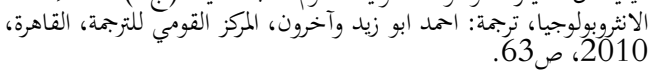

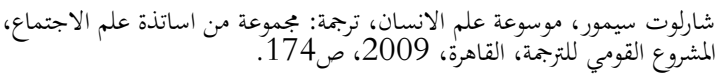

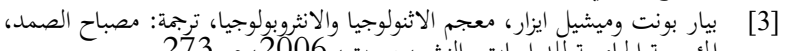

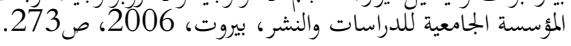

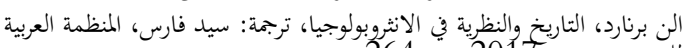

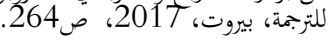

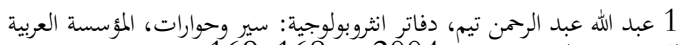

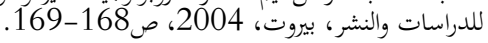

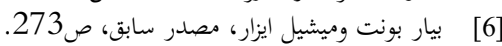

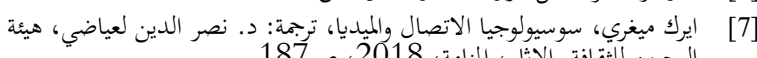

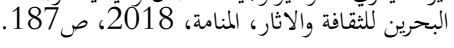

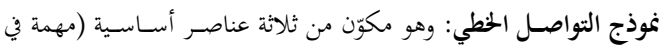

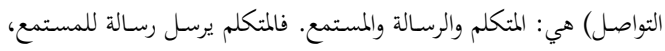

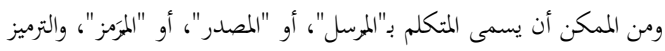

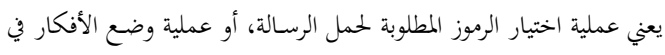

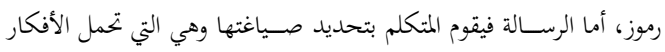

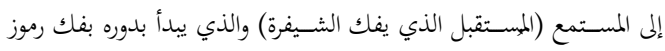

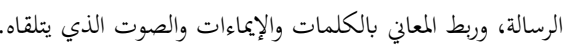

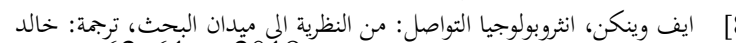

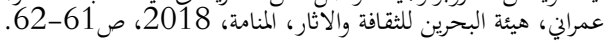

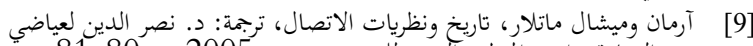

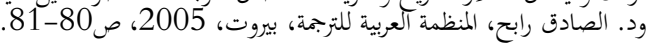

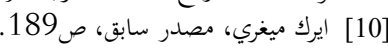

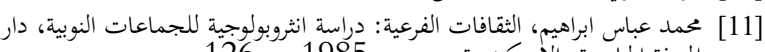

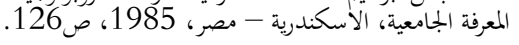

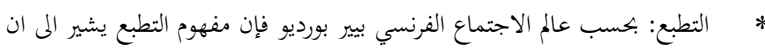

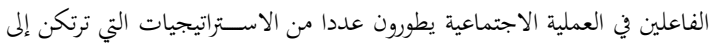

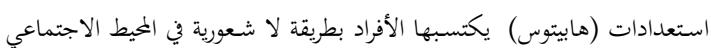

انـه ارتأى ان يعيـد انتـاجهـا جميعـاً، وجعلهـا تـدور في محور مفهوم الصـراع، وبحسب فهمنا فإن القاعدة الاسـاسـية لنظرية باتيسـون هي

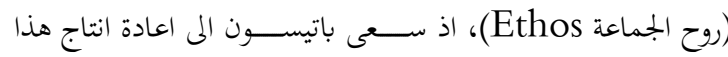

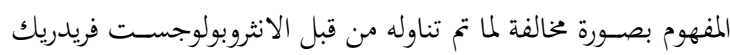

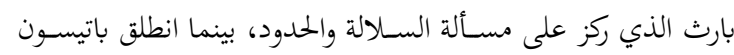

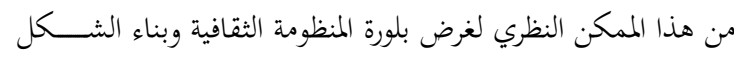

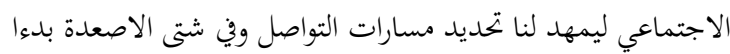

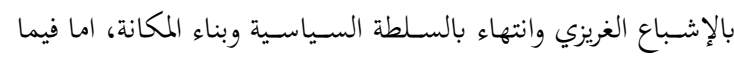
يتعلق بالافتراضـات النظرية التي تمثل الاذرع التحليلية يأتي مفهوم روح

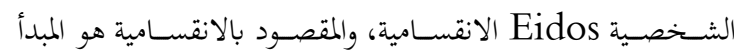
التقابلي اي التقابل داخل المجموعة الواحدة لغرض بناء المقارنة وبناء النمط وتحديده، وكذلك بين مجموعتين لغرض فهم المرتكزات اللولبية

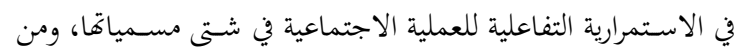

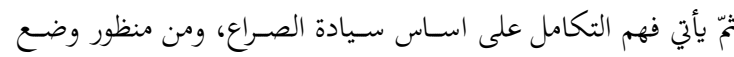

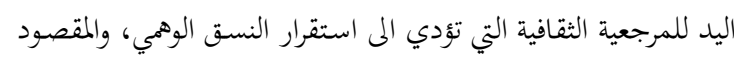

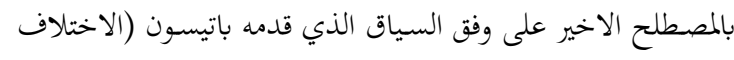

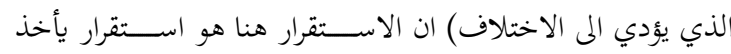
شكالً ظاهرياً ويموي مضموناً ثقافياً متصارعاً.

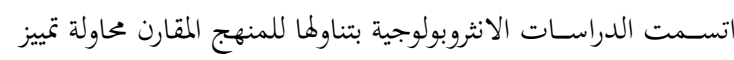
.3 تناولها عن المفهوم او التخصــص التاريخي، وقد ارتســـم هذا المنهج التقليدي في الانثروبولوجيا على وفق المقـارنة الافقيـة والعمودية التي

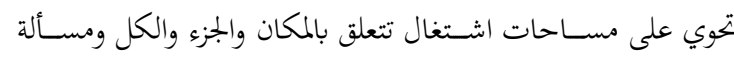

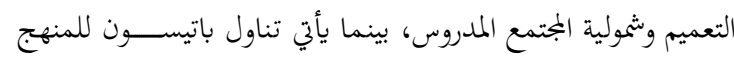
المقارن على وفق متقابلات مفاهيمية متلئة بالعناصر والسمات والقيم والاعراف الاجتماعية لكي ترتسم من خلالما المقارنة في سياق جماعة

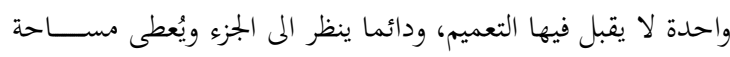

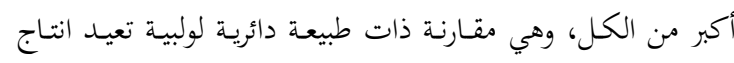
العملية الاجتماعية على وفق جمع نتاجات المقارنات على وفق اربع

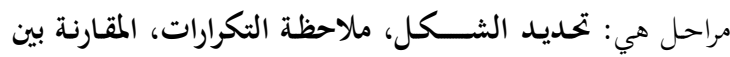
التكرارات، وتحليل النمط الظاهر للتشـكّل، وهو منظور يبتعد كثيرا

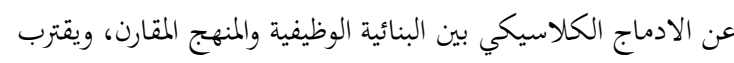
نوعا ما من الاثنوجرافيا الحديثة وتوجهات الانثروبولوجسـت جلئيف بليفورد

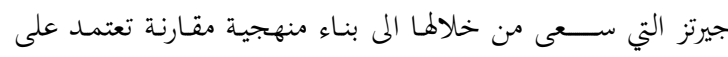
التصورات المتكررة لتوليد الانماط.

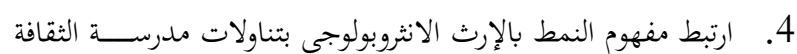
والشخصية وتعلق بمسألة التنشئة الاجتماعية لبناء الشخصية والذي جرى فهمه في العديد من الدراســـات من خلال المقارنة بين الانماط يماء

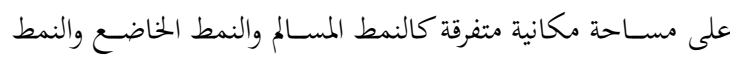

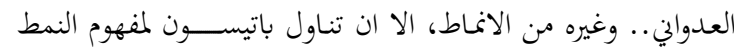
ختلف عن تلك التناولات على الرغم من انه انتج معطياته من خلال 
[49] الطاهر لبيب, مصدر سابق، ص639.

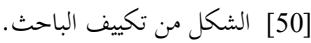

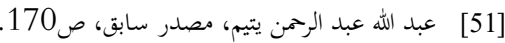

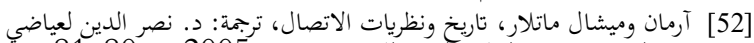

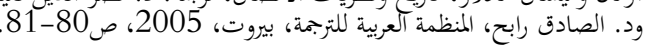

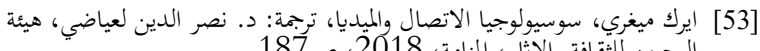

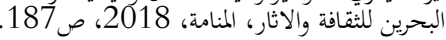

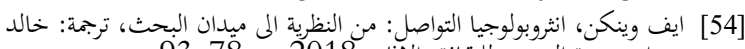

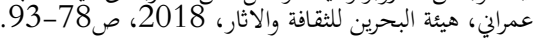

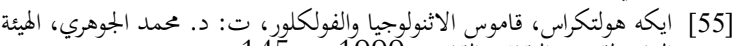

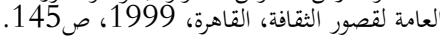

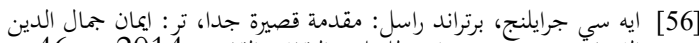

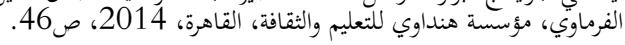

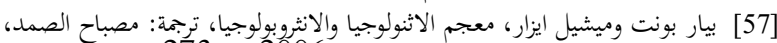

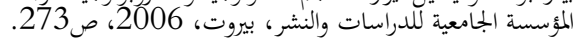

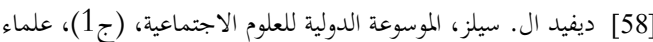

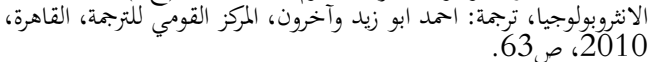

[59] السيد حافظ الاسود، الانثروبولوجيا الرمزية: دراسة نقدية مقارنة للاتحاهات الحديثة

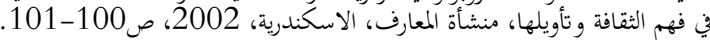

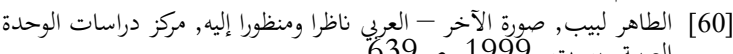

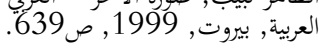

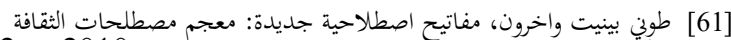

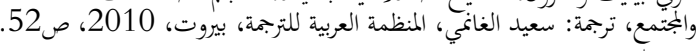

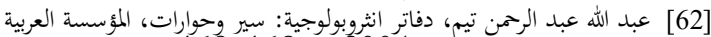

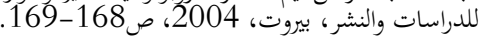

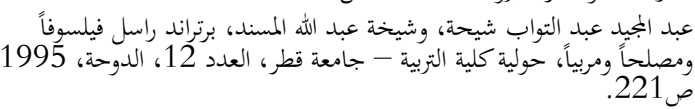
[64] عمر مهيبل، البنيوية في الفكر الفلسفي، ديوان المطبوعات الجامعية، الطبعة الثانية،

[65] فاروق محمد اسماعيل، الملدخل 1987 الى الانثروبولوجيا: النظرية والمنهج، دار المعرفة

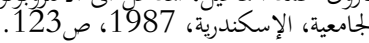

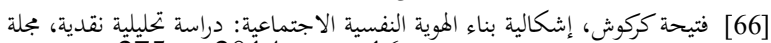

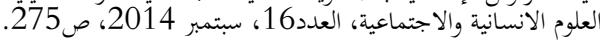

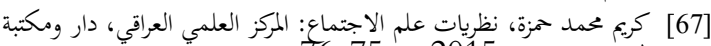

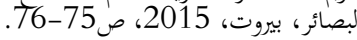

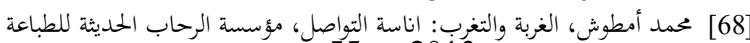

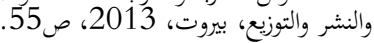

[69] محمد عباس ابراهيم، الثقافات الفرعية: 2013، صراسة انثروبولوجية للجماعداعات النوبية، دار

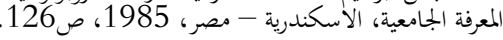

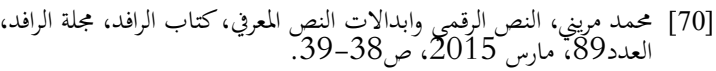

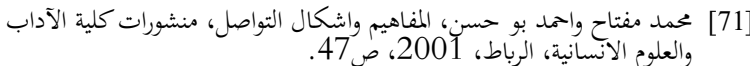

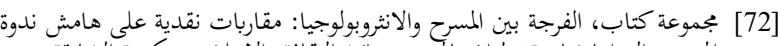

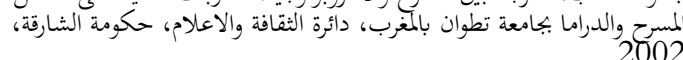

[73] مصطفى ناصف، نظريات التعلم، تربمة: علي حسين حجاجة، المجلس الوطني

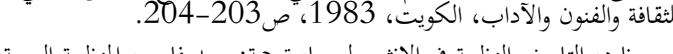

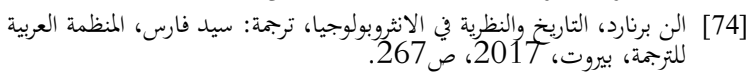

[75] وحيدة سعدي، بالو التو مدرسة الاتصال، بجلة دراسات، التحاد ادباء وكتاب التاب

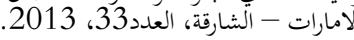

Lawrence S. Bale, Gregory Bateson's Theory of [76] Practical Applications to Pedagogy, Down 'n :Mind Out Press November 1992
والثقافي تمكِّنهم من التكيف وخلق نمط جديد من السـلوكيات الطارئة المنسـجمة مع ضرورات الخيط الاجتماعي.

Lawrence S. Bale, Gregory Bateson's Theory of [12] Practical Applications to Pedagogy, Down 'n :Mind Out Press November 1992, p16.

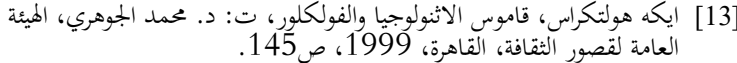

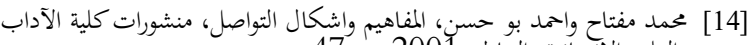

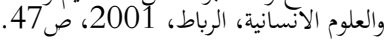

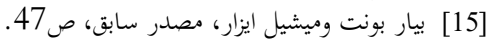

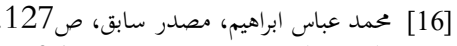

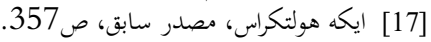

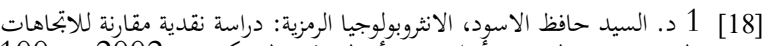

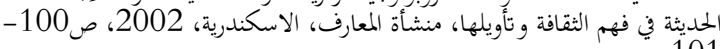

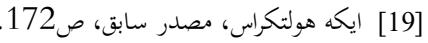

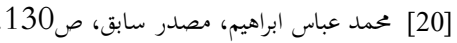

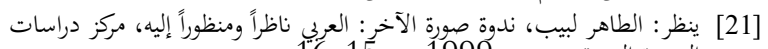

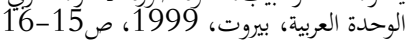

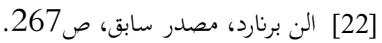

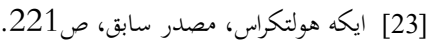

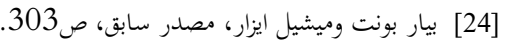

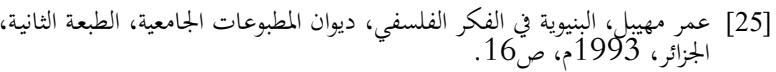

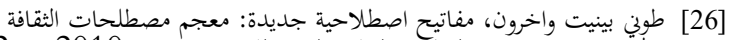

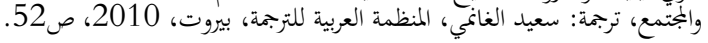

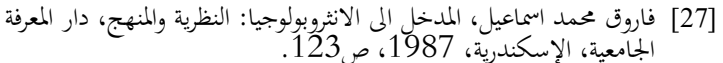

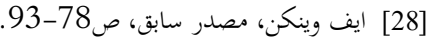

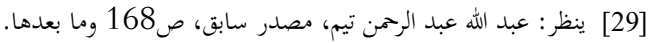

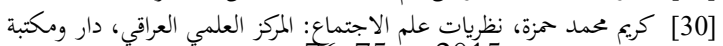

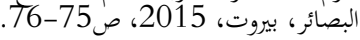

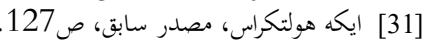

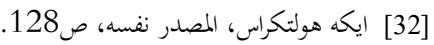

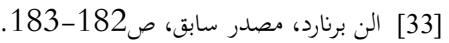

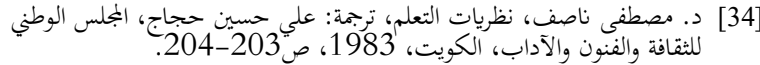

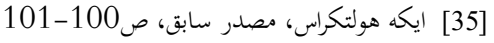

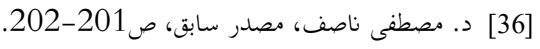

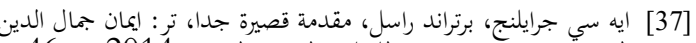

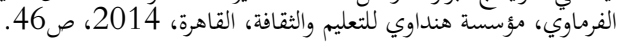

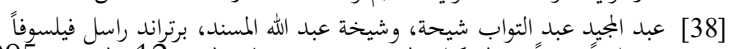

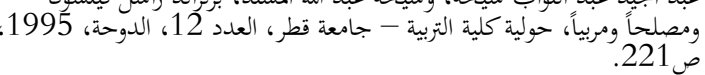

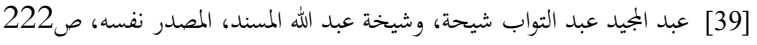

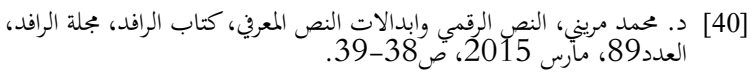

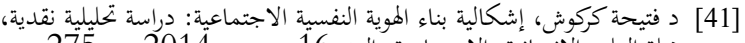

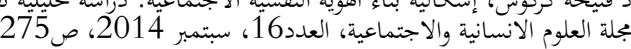

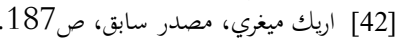

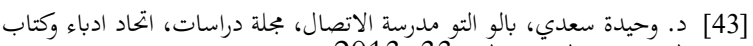

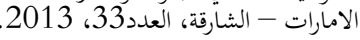

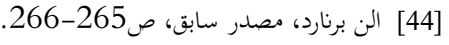

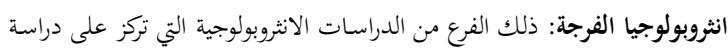

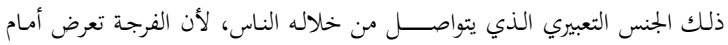

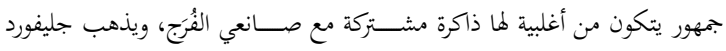

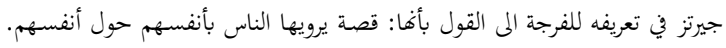

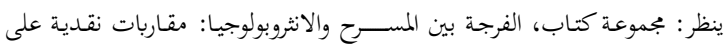

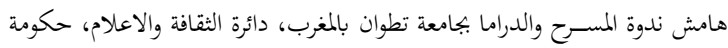

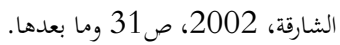

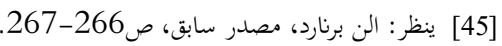

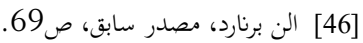

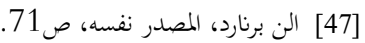

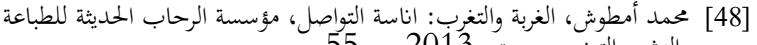

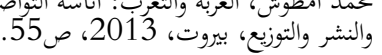


